\title{
InCENTIVES AND THE DE Soto EFFECT*
}

\author{
Timothy J. Besley \\ KONRAD B. BURCHARDi \\ Maitreesh GHATAK
}

August 2011.

\begin{abstract}
This paper explores the consequences of improving property rights to facilitate the use of fixed assets as collateral, popularly attributed to the influential policy advocate Hernando de Soto. We use an equilibrium model of a credit market with moral hazard to characterize the theoretical effects, and also develop a quantitative analysis using data from Sri Lanka. We show that the effects are likely to be non-linear and heterogeneous by wealth group. They also depend on the extent of competition between lenders. There can be significant increases in profits and reductions in interest rates when credit markets are competitive. However, since these are due to reductions in moral hazard, i.e. increased effort, the welfare gains tend to be modest when cost of effort is taken into account. Allowing for an extensive margin where borrowers gain access to the credit market, can make these effects larger depending on the underlying wealth distribution.
\end{abstract}

Keywords: Credit markets, collateral, property rights.

JEL Codes: D23, O12, O16, Q15

*We thank Abhijit Banerjee, Pranab Bardhan, Sam Bowles, Ravi Kanbur, Fahad Khalil, Rocco Machiavello, the Editor, Elhanan Helpman, the anonymous referees, and several seminar audiences for helpful feedback. We are grateful to Christopher Woodruff and David McKenzie for their generous help with access to the data from their Ghana and Sri Lanka studies. The usual disclaimer applies.

Contact: t.besley@lse.ac.uk, k.b.burchardi@lse.ac.uk, m.ghatak@lse.ac.uk; London School of Economics, Houghton Street, London WC2A 2AE. 


\section{Introduction}

Developing countries are plagued with market and institutional imperfections. A key symptom of this is the finding that the marginal product of capital is considerably higher than prevailing interest rates. ${ }^{1}$ Such capital market imperfections result in the misallocation of capital, lower productivity, and can even lead to poverty traps. No wonder, therefore, that policy initiatives have focused on dealing with the underlying causes of capital market frictions.

One important such initiative aimed at improving the workings of capital markets involves extending and improving property rights so that assets can be pledged as collateral for loans. This has become a cause célèbre of Hernando de Soto ${ }^{2}$ whose view is stated succinctly in the following quote:

"What the poor lack is easy access to the property mechanisms that could legally fix the economic potential of their assets so that they could be used to produce, secure, or guarantee greater value in the expanded market...Just as a lake needs hydroelectric plant to produce usable energy, assets need a formal property system to produce significant surplus value." (De Soto, 2001).

This idea has captured the imagination of policy makers, is frequently proclaimed as a magic bullet and has been taken up all over the world. We therefore refer to the idea that better access to collateral through improving property rights improves the workings of credit markets as the de Soto effect. ${ }^{3}$

This paper develops a theoretical model to explore the nature and magnitude of the de Soto effect. We use the model to derive predictions on the effect of improving property rights on credit contracts in an equilibrium setting. We then explore these effects quantitatively using a data set from Sri Lanka collected by de De Mel et al. (2008) which conducts an experiment which can be used to deduce a key structural parameter in our model. The quantitative analysis shows that the effect of property rights improvements is likely to be both non-linear and heterogeneous. In particular, we highlight how the effect of property rights improvements varies at different wealth levels and with the extent of competition in the credit market.

Our theoretical model also allows us to look at the welfare gains from improving property rights. In the absence of competition in the credit market, borrowers may actually be worse off.

\footnotetext{
${ }^{1}$ See Banerjee (2003), Banerjee and Duflo (2010) for overviews and De Mel et al. (2008) for evidence from a randomized controlled trial in Sri Lanka.

${ }^{2}$ See, for example, De Soto $(2000,2001)$. See Woodruff (2001) for a review of de Soto's argument.

${ }^{3}$ It is arguable that this should really be called the Bauer-de Soto effect since this link was also spotted by Peter Bauer in his perceptive account of West African trade wherein he argues that:

"Both in Nigeria and in the Gold Coast family and tribal rights in rural land is unsatisfactory for loans. This obstructs the flow and application of capital to certain uses of high return, which retards the growth of income and hence accumulation." (Bauer, 1954, p. 9).
} 
Even with competition, we estimate relatively modest utility gains - around $2 \%$ of the value of the average annual labor endowment of a small business owner. This is true in spite of expected profits increasing. However, these are achieved by increasing effort, the cost of which should be taken into account when assessing the impact on welfare.

The paper fits into a much older tradition in development economics which explores contracting models for low income environments (see Stiglitz, 1988, and Banerjee, 2003, for reviews). However, in contrast to most of that literature, we offer an innovative twist by developing an application which provides a bridge between empirical work and policy evaluation. This allows us to demonstrate that ideas from the theory of the second-best can indeed have practical relevance for policy. Trying property rights reform in an environment where there is an additional distortion, i.e. competition is weak, can be quite a different proposition from doing so when competition is strong. So while there is a compelling theoretical logic to the de Soto effect, its quantitative significance and welfare consequences depend on the environment in which property rights improvements are being contemplated. This can explain the rather mixed empirical findings from the regression evidence linking measures of credit market performance to property registration possibilities.

The functioning of capital markets is now appreciated to be a key determinant of the development process (see Banerjee, 2003, for a review). Within this, the issue of how legal systems support trade in credit, labour, and land markets is a major topic. For example, Kranton and Swamy (1999) show how the introduction of civil courts in colonial India increased competition among lenders while undermining long-term relationships among borrowers and lenders by making it easier for borrowers to switch lenders. Genicot (2002) shows how banning bonded labour generates greater competition between landlords and moneylenders thereby improving the welfare of poor farmers. Genicot and Ray (2006) study the effects of a change in the outside options of a potential defaulter on the terms of the credit contract, as well as on borrower payoffs in the presence of enforcement constraints.

Our work is also related to the macro-economic literature which studies how aspects of legal systems affect the development of financial markets. One distinctive view is the legal origins approach associated with La Porta et al. (1998). They argue that whether a country has a civil or common law tradition is strongly correlated with the form and extent of subsequent financial development with common law countries having more developed financial systems. In similar vein, Djankov et al. (2007) find that improvements in rights which affect the ability of borrowers to use collateral are strongly positively correlated with credit market development in a cross-section of countries. The economics literature now recognizes the fundamental importance of improving property rights in the process of economic development. The well-known paper of Acemoglu, Johnson, and Robinson (2001) provided fresh impetus to these ideas and found robust correlations between measures of expropriation risk and income per capita in cross-country data.

The empirical evidence on the impact of property rights improvements using micro-data is 
somewhat equivocal in its findings. ${ }^{4}$ And, in similar vein, Acemoglu and Johnson (2005) find that contracting institutions appear to do a less good job in explaining income differences. This is consistent with the findings here where we would expect effects to be heterogeneous across households and institutional settings. Specifying the underlying model is helpful in pin pointing potential sources of heterogeneity and exploring how they might affect the magnitude of reducedform estimates.

A number of papers have empirically explored the effect that collateral improvement has on credit contracts (see, for example, Liberti and Mian, 2010). Looking at the literature as a whole, the empirical estimates vary widely and are context specific. There is very little in the existing literature to help think about why this might be. Our theoretical model and the quantitative application can help to think about some of the reasons why this might be the case.

The remainder of the paper is organized as follows. The next section introduces our core model of credit market contracting and section three uses this to study second-best efficient credit contracts. This section also characterizes the market equilibrium where lenders compete to serve borrowers. Section four explores some positive and normative implications of the model. Section five provides a quantitative assessment of the effects that we identify by parametrising the model using estimates based on data from Sri Lanka and Ghana. Section six looks at some extensions to our basic model, namely, introducing a fixed cost, and considering alternative dimensions of competition, such as those from informal lenders. Section seven concludes.

\section{The Model}

The model studies contracting between borrowers and lenders. We use a variant of a fairly standard agency model (see Innes, 1990) that is frequently used to analyze contractual issues in development. The borrower's effort is subject to moral hazard and in addition, he has limited pledgeable wealth resulting in limited liability. We add to this the following friction: contract enforcement is limited due to imperfections in property rights protection which reduce the collateralizability of wealth.

Borrowers There is a group of borrower-entrepreneurs whose projects benefit from access to working capital provided by lenders. Each borrower is assumed to be endowed with a level of illiquid wealth $w$ (e.g., a house or a piece of land). We will study the optimal contract with a fixed value of $w$. However, in our application, we allow for borrowers to differ in their wealth levels.

We assume that property rights are poorly defined in a way that affects the borrowers' ability

\footnotetext{
${ }^{4}$ Besley and Ghatak (2009) review these ideas in general and discuss different theoretical mechanisms. Deininger and Feder (2009) provide a detailed review of the empirical literture. Contributions to the empirical literature include Besley (1995), Field (2005, 2007), Field and Torero (2008), Galiani and Schargrodsky (2010), Goldstein and Udry (2008), Hornbeck (2010), and Johnson et al. (2002).
} 
to pledge their wealth as collateral. We introduce a parameter $\tau$ that captures this. Specifically, we assume that if a borrower has wealth $w$ then its collateral value is only $(1-\tau) w$. So $\tau=0$ corresponds to perfect property rights whereas $\tau=1$ corresponds to the case where property rights are completely absent. We can think of $\tau$ as the fraction of the collateral which cannot be seized or the probability that the collateral cannot be seized. We will refer to $(1-\tau) w$ as a borrower's effective wealth.

Each borrower supplies effort $e \in[0, \bar{e}]$ and uses working capital $x \in[0, \bar{x}]$ to produce an output. Output is stochastic and takes the value $q(x)$ with probability $p(e)$ and 0 with probability $1-p(e)$. The marginal cost of effort is normalized to 1 and the marginal cost of $x$ is $\gamma \cdot{ }^{5}$ Expected 'surplus' is therefore:

$$
p(e) q(x)-e-\gamma x
$$

Throughout the analysis we make the following assumption.

Assumption 1 The following conditions hold for the functions $p(e)$ and $q(x)$ :

(i) Both $p(e)$ and $q(x)$ are twice-continuously differentiable, strictly increasing and strictly concave for all $e \in[0, \bar{e}], x \in[0, \bar{x}]$.

(ii) $p(0)=0, p(\bar{e}) \in(0,1]$, and, $q(0) \geq 0$.

(iii) $\lim _{e \rightarrow 0} p^{\prime}(e) q(x)>1$ for all $x>0, \lim _{x \rightarrow 0} p(e) q^{\prime}(x)>\gamma$ for all $e>0, p^{\prime}(\bar{e}) q(\bar{x})<1$, and $q^{\prime}(\bar{x}) p(\bar{e})<\gamma$.

(iv) $p(e) q(x)$ is strictly concave for all $(e, x) \in[0, \bar{e}] \times[0, \bar{x}]$.

(v) $\epsilon(e) \equiv-p^{\prime \prime}(e) p(e) /\left\{p^{\prime}(e)\right\}^{2}$ is bounded and continuous for $e \in[0, \bar{e}]$, and $p^{\prime \prime \prime} \leq-\frac{p^{\prime \prime} p^{\prime}}{p}$.

Most standard examples of concave functions of one variable (or their affine transformations) satisfy properties (i)-(iv). ${ }^{6}$ They are sufficient conditions to ensure that we have a well-defined optimization problem with interior solutions. The first part of $(\mathrm{v})$ is a technical assumption which ensures a unique interior solution in the second-best. The second part of (v) stipulates that the degree of concavity of the function $p(e)$ does not decrease too sharply. This ensures that the richer is the borrower, the costlier it is to elicit effort.

\footnotetext{
${ }^{5}$ In the empirical analysis, we will allow for the cost of effort to be $\eta e$ where $\eta$ is a parameter that is estimated in the data from the wage rate.

${ }^{6}$ For example, they hold for Cobb-Douglass: $p(e)=e^{\alpha}$ and $q(x)=x^{\beta}$ where $\alpha \in(0,1), \beta \in(0,1), \alpha+\beta<1$. With suitable choice of parameters, they are satisfied by the quadratic and CES as well (e.g., for $p(e)$, the functional forms would be $p_{0}+p_{1} e-p_{2} e^{2}$ where $p_{i}>0$ for $i=0,1,2$ and $p_{0}+p_{1}\left(1+e^{-\alpha}\right)^{-\frac{1}{\alpha}}$ where $\left.-1 \leq \alpha \neq 0\right)$.
} 
Lenders We use the simplest possible set-up that can allow for competition in the credit market and assume that there are two lenders $(j=1,2)$ who borrow funds from depositors or in wholesale markets to fund their lending. The more efficient lender has marginal cost of funds $\underline{\gamma}$ while the less efficient lender has marginal cost $\bar{\gamma}$ with $\bar{\gamma} \geq \underline{\gamma}$. We assume that each lender has unlimited capacity to supply the market. ${ }^{7}$

In the case where $\bar{\gamma}=\underline{\gamma}$, these market lenders are equally efficient and we are effectively in the case of Bertrand competition with identical costs. To the extent that $\bar{\gamma}$ is greater than $\underline{\gamma}$ the low cost lender may be able to earn a rent relative to the outside option of borrowers of borrowing from the less efficient lender. Thus $\bar{\gamma}-\gamma$ will effectively be a measure of market competitiveness.

We can interpret this set up as one where lenders are financial intermediaries that borrow money from risk neutral depositors whose discount factor is $\delta$. Financial intermediary $j$ repays depositors with probability $\mu_{j}$. This could reflect intrinsic trustworthiness or the state of the intermediary's balance sheet, e.g. its wealth. In this case $\gamma_{j}=1 /\left(\delta \mu_{j}\right)$ is intermediary $j$ 's cost of funds which is lower for more trustworthy intermediaries. Naturally, $1 / \delta$ sets a lower bound for the marginal cost of capital.

\section{Contracting}

We assume that $e$ is not contractible. This would not be a problem if a borrower had sufficient wealth to act as a bond against non-repayment. However, limits on the amount of wealth that can be effectively pledged as collateral will be an important friction preventing the first-best outcome being realized. Even if the borrower's liquid wealth is sufficient for this purpose, poorly defined property rights, as argued by De Soto (2001), may place a further limit.

A credit contract is a triple $(r, c, x)$ where $r$ is the payment that he has to make when the project is successful, $c$ is the payment to be made when the project is unsuccessful, and $x$ is the loan-size. ${ }^{8}$ It will be useful to think of $r$ as the repayment and $c$ as collateral. The payoff of a borrower is:

$$
p(e)[q(x)-r]-(1-p(e)) c-e
$$

and the payoff of a lender is:

$$
p(e) r+(1-p(e)) c-\gamma x .
$$

Let the borrower's outside option be $u \geq 0$. In the next two subsections, we will solve for the first and second best efficient contracts offered by a lender with cost of funds $\gamma$, taking $u$ as exogenous.

\footnotetext{
${ }^{7}$ The assumption of two lenders is without loss of generality given these assumptions by applying the standard logic of Bertrand-competition, where the relevant competition for a borrower will always be between one lender and the next most attractive alternative lender.

${ }^{8}$ Innes (1990) shows that even if output took multiple values or was continuous, the optimal contract has a two part debt-like structure as here.
} 
The outside option will be determined endogenously once we permit lenders to compete to serve borrowers. ${ }^{9}$ We assume that lenders must make non-negative profits in order to be active in the credit market.

\subsection{The First Best}

In the absence of any informational or contractual frictions so that effort is contractible we will see effort and lending chosen to maximize the joint surplus of borrower and lender, $p(e) q(x)-e-\gamma x$. The first-best $\left(e^{*}(\gamma), x^{*}(\gamma)\right)$ allocation is characterized by the following first-order conditions:

$$
\begin{aligned}
& p^{\prime}\left(e^{*}(\gamma)\right) q\left(x^{*}(\gamma)\right)=1 \\
& p\left(e^{*}(\gamma)\right) q^{\prime}\left(x^{*}(\gamma)\right)=\gamma
\end{aligned}
$$

where the marginal product of effort and capital are set to equal to their marginal costs. Effort and credit are complementary inputs in this framework. So a fall in $\gamma$ or anything that increases the marginal product of effort or capital will raise the use of both inputs.

The first-best surplus is denoted by

$$
S^{*}(\gamma)=p\left(e^{*}(\gamma)\right) q\left(x^{*}(\gamma)\right)-e^{*}(\gamma)-\gamma x^{*}(\gamma)
$$

which is decreasing in $\gamma$. It is efficient in this case to have all credit issued by the lowest cost lender who has cost of funds $\underline{\gamma}$. The profit of this lender, denoted by $\pi$, is equal to $\max \left\{S^{*}(\underline{\gamma})-u, 0\right\}$, i.e. respects the lender's option to withdraw from the market. ${ }^{10}$

\subsection{Second Best Contracts}

In reality, contracts are constrained by information and limited claims to wealth that can serve as collateral. Given the contract $(r, c, x)$, the borrower will choose effort as the solution to:

$$
\max _{e} p(e)[q(x)-r]-(1-p(e)) c-e
$$

The first-order condition yields the incentive compatibility constraint (ICC) on effort by the borrower:

$$
p^{\prime}(e)\{q(x)-(r-c)\}=1
$$

defining $e$ implicitly as $e(r, c, x)$.

\footnotetext{
${ }^{9}$ Observe that we are defining borrower payoffs net of any consumption value that he gets from his wealth which may, for example, be held in the form of housing.

${ }^{10}$ Notice that the borrower's outside option is to either go to the other lender or autarchy. The latter is characterized by an effort level $e_{a}=\arg \max _{e} p(e) q(0)-e$ and gives the autarchic utility level $u_{a}=p\left(e_{a}\right) q(0)-e_{a}$ which is non-negative, and zero when $q(0)=0$. Under our assumption the first-best is characterized by an interior solution. Hence it must be the case that in the first-best $u=\max \left\{S^{*}(\bar{\gamma}), u_{a}\right\}=S^{*}(\bar{\gamma})$.
} 
Efficient contracts between a lender and a borrower now solve the following problem:

$$
\max _{\{r, c, x\}} \pi(r, c, x)=p(e) r+(1-p(e)) c-\gamma x
$$

subject to:

(i) the participation constraint (PC) of the borrower

$$
p(e)\{q(x)-r\}-(1-p(e)) c-e \geq u,
$$

(ii) the ICC

$$
e=e(r, c, x)
$$

(iii) the limited liability constraint (LLC)

$$
(1-\tau) w \geq c
$$

We describe the optimal second best contract in two parts. First, we consider when the first best can be achieved (Proposition 1). Then we consider what happens when this is not the case (Proposition 2). It is useful to define

$$
v \equiv u+(1-\tau) w
$$

as the sum of the borrower's outside option and his effective wealth.

Intuitively, we would expect the first best to be achievable when the borrower has sufficient effective wealth to pledge as collateral. To make this precise, define

$$
\bar{v}(\gamma) \equiv S^{*}(\gamma)+\gamma x^{*}(\gamma)
$$

as the level of $v$ equal to the first best surplus plus the cost of credit where the amount lent is at the first-best level. Observe that for lending to occur, there needs to be non-negative net surplus, i.e., $u \leq S^{*}(\gamma)$. We find: ${ }^{11}$

Proposition 1 Suppose that Assumption 1 (i)-(iv) holds. Then for $v \geq \bar{v}(\gamma)$ and $u \leq S^{*}(\gamma)$ the first-best outcome is achieved with

$$
\begin{aligned}
r=c & =\gamma x^{*}(\gamma)+S^{*}(\gamma)-u \\
x & =x^{*}(\gamma) \\
e & =e^{*}(\gamma) .
\end{aligned}
$$

It is straightforward to check that the condition stated in Proposition 1 that $v \geq \bar{v}(\gamma)$ is equivalent

\footnotetext{
${ }^{11}$ The proof of this and all subsequent results is in the Appendix.
} 
to $(1-\tau) w \geq S^{*}-u+\gamma x^{*}(\gamma)$. This says that the borrower's effective wealth must be greater than the part of the surplus which the lender can extract plus the cost of credit. In this case, it is possible for the borrower to make a fixed payment to the lender by pledging a portion of his wealth against default. He then becomes a full residual claimant on the returns to effort, a requirement for the first-best effort level to be chosen by the borrower. The fact that the wealth threshold includes the outside option of the borrower implies that the first best will be easier to achieve in competitive credit markets where the outside option is high.

If $v<\bar{v}(\gamma)$, or, $(1-\tau) w<\bar{v}(\gamma)-u$, the constraint $c \leq(1-\tau) w$ will be binding and it will not be possible to achieve the first best. Our result for this case is given by:

Proposition 2 Suppose that Assumption $1(i)$ - $(v)$ holds. There exists $\underline{v}(\gamma) \in(0, \bar{v}(\gamma))$ such that for $v<\bar{v}(\gamma)$ the optimal contract is as follows:

$$
\begin{aligned}
& c=(1-\tau) w, \\
& r=\left\{\begin{array}{ll}
\rho(\underline{v}(\gamma), \gamma)+(1-\tau) w & v<\underline{v}(\gamma) \\
\rho(v, \gamma)+(1-\tau) w & v \in[\underline{v}(\gamma), \bar{v}(\gamma))
\end{array}>c,\right. \\
& x= \begin{cases}g(\underline{v}(\gamma), \gamma) & v<\underline{v}(\gamma) \\
g(v, \gamma) & v \in[\underline{v}(\gamma), \bar{v}(\gamma))\end{cases}
\end{aligned}
$$

where $\rho(v, \gamma)=q(g(v, \gamma))-\frac{1}{p^{\prime}(f(v))}$ and $g(v, \gamma)$ and $f(v)$ are strictly increasing in $v$ while $g(v, \gamma)$ is strictly decreasing in $\gamma$. It implements

$$
e= \begin{cases}f(\underline{v}(\gamma)) & v<\underline{v}(\gamma) \\ f(v) & v \in[\underline{v}(\gamma), \bar{v}(\gamma))\end{cases}
$$

The intuition for this result is the following: Since $v<\bar{v}(\gamma)$, the level of wealth is insufficient to achieve the first best - both effort and credit granted are below their first best levels. All effective wealth is pledged as collateral and the repayment made when the project is successful exceeds that when it fails. The level of that payment reflects the standard trade-off between extracting more rent from the borrower by raising $r$ and reducing the borrower's effort as a consequence. There is also the participation constraint of the borrower to take into account: even if the lender might be willing to raise $r$ at the expense of $e$, he may be constrained by the fact that the borrower has to be given a minimum payoff which is determined by his outside option.

In the second best, there are two sub-cases which play a role throughout the ensuing analysis, corresponding to whether the participation constraint binds or not. The first case will tend to apply when either a borrower's outside option is very poor or their effective wealth is extremely low a case where the de Soto effect logic is frequently applied. For a borrower whose outside option is very poor and/or whose effective wealth is very low the participation constraint clearly cannot bind. For example, in the extreme case where $u=w(1-\tau)=0$ this would require giving 
no loans to the borrower or, setting $r=q(x)$ both of which will yield the lender zero profits. In general, when $u$ and $w(1-\tau)$ are low (the precise condition being $v \leq \underline{v}(\gamma)$ ) the participation constraint is not binding and the lender will choose an $r$ that maximizes his expected profits subject to the incentive-compatibility constraint (and the binding limited liability constraint). Stated differently, imagine the lender would set $r$ such that the participation constraint of the borrower is binding. What we find is that, given there are sufficiently high returns to effort at low levels of effort and capital, the lender will find it worthwhile to decrease $r$ (the payment he receives in the case of success) to induce higher effort (and hence make success more likely).

In this case $(v \leq \underline{v}(\gamma))$ the lender will offer an amount of credit and elicit an effort level which is independent of the actual value of $u$ or $w(1-\tau)$. The borrower will receive an expected payoff which exceeds his outside option, i.e., he will receive an "efficiency utility" level, analogous to an efficiency wage in the literature on labor markets. As $(1-\tau) w$ increases the lender can extract more from the borrower in the event of default. He can now extract more surplus from the borrower by raising $c$ and $r$ by the same amount, leaving the effort level unchanged and making the borrower worse off.

In the second case $v \in[\underline{v}(\gamma), \bar{v}(\gamma)]$, where $\underline{v}$ is defined by the point where the outside option is high enough, such that $r$ can no longer be set as above and must be reduced to satisfy the borrower's participation constraint. This is a more conventional case where both the incentive compatibility and participation constraints are binding. The lender will still want to set $c=(1-\tau) w$, as setting a lower $c$ rather than a lower $r$ would reduce the borrower's effort. A higher wealth level or a better outside option now increases effort and the amount of credit supplied by the lender.

Let

$$
S(v, \gamma) \equiv \begin{cases}S^{*}(\gamma) & v \geq \bar{v}(\gamma) \\ p(f(v)) q(g(v, \gamma))-f(v)-\gamma g(v, \gamma) & v \in(\underline{v}(\gamma), \bar{v}(\gamma)) \\ p(f(\underline{v})) q(g(\underline{v}, \gamma))-f(\underline{v})-\gamma g(\underline{v}, \gamma) & v \leq \underline{v}\end{cases}
$$

be the total surplus of the lender and the borrower with the contract described in Propositions 1 and 2. Since effort $f(v)$ is increasing in $v$ when the participation constraint is binding, and it is under-supplied relative to the surplus maximizing level, $S(v, \gamma)$ is strictly increasing in $v$ for $v \in[\underline{v}(\gamma), \bar{v}(\gamma)]$. If the participation constraint is not binding $(v<\underline{v}(\gamma))$ or the first-best is attainable $(v \geq \bar{v}(\gamma))$ then $S(v, \gamma)$ is constant with respect to $v .^{12}$

\subsection{Market Equilibrium}

We introduce competition by allowing the lenders to compete to attract borrowers by posting contracts $(r, c, x)$. Borrowers then pick the lender that gives them the highest level of expected

\footnotetext{
${ }^{12}$ Also since the amount of the loan $g(v, \gamma)$ is always decreasing in $\gamma$, so is, $S(v, \gamma)$. See Lemma 1 in the Appendix for a formal proof of the properties of $S(v, \gamma)$.
} 
utility. This market game is essentially a model of Bertrand competition between the lenders. The contractual terms will be selected from the set of second-best Pareto efficient contracts described in Propositions 1 and 2. Otherwise, the lender can make a greater profit without the borrower being worse off. The outside option is given by the utility received if he were to choose to borrow from the other lender.

Let the market equilibrium payoffs for the borrower borrowing from the efficient and inefficient lender be denoted by $u_{\underline{\gamma}}$ and $u_{\bar{\gamma}}$ with corresponding profits for the lenders being denoted by $\pi_{\underline{\gamma}}$ and $\pi_{\bar{\gamma}}$. (Feasibility further requires that $\pi_{\underline{\gamma}}, \pi_{\bar{\gamma}} \geq 0$.) It is also clear that $u_{\underline{\gamma}}, u_{\bar{\gamma}} \geq u_{a}$.

Since the contractual terms are characterized by Propositions 1 and 2, the payoffs of the borrowers and lenders must exhaust the available surplus in the borrower-lender relationship and hence solve:

$$
\begin{aligned}
& S\left(u_{\bar{\gamma}}+(1-\tau) w, \underline{\gamma}\right)=\pi_{\underline{\gamma}}+u_{\underline{\gamma}} \\
& S\left(u_{\underline{\gamma}}+(1-\tau) w, \bar{\gamma}\right)=\pi_{\bar{\gamma}}+u_{\bar{\gamma}} .
\end{aligned}
$$

Now define $\bar{u}((1-\tau) w, \bar{\gamma})$ from $S(u+(1-\tau) w, \bar{\gamma})=u$ as the maximum utility that the high cost lender can offer consistent with him making non-negative profits. The lenders will compete by offering higher utility levels to the borrower up to this point.

The market equilibrium divides up the surplus between lenders and borrowers. The intensity of competition is determined by $\bar{\gamma}-\underline{\gamma}$, the difference in the cost of funds of the efficient and inefficient lenders. The following result describes the outcome:

Proposition 3 In a market equilibrium, the least efficient lender makes zero profit and the borrower borrows from the efficient lender. For borrower utility, there are two cases:

1. If competition is weak enough, he receives his efficiency utility level from the efficient lender.

2. If competition is intense enough, then the borrower receives his outside option available from the inefficient lender.

So if there is little competition, the lender now captures most of the surplus and the borrower is driven down to his efficiency utility. Formally, $\bar{u}((1-\tau) w, \bar{\gamma})+(1-\tau) w<\underline{v}(\underline{\gamma})$ with $u_{\underline{\gamma}}=\underline{v}(\underline{\gamma})-(1-\tau) w$. The credit contract now resembles the first case in Proposition 2 above. This happens when the efficient lender enjoys a significant cost advantage. If the efficient and inefficient lenders have similar costs of funds, most of the surplus in the relationship is captured by the borrower (the first case) and the efficient lender make small profits. Formally, this will be the case when $\bar{u}((1-\tau) w, \bar{\gamma})+(1-\tau) w \geq \underline{v}(\underline{\gamma})$, so that $u_{\gamma}=u_{\bar{\gamma}}=\bar{u}((1-\tau) w, \bar{\gamma})$. The credit contract in this market equilibrium is then the second case in Proposition 2. 


\section{The Model at Work}

We now explore some positive and normative implications of the model. Specifically, we are interested in what happens when $\tau$ is reduced so that more wealth can be used as collateral.

\subsection{Implications for Credit Contracts}

We first consider what happens to credit contracts as $\tau$ varies. We identify two underlying effects: a limited liability effect and a competition effect.

Proposition 4 Suppose that property rights improve so that more collateral can be pledged by borrowers. Then the impact depends on which of the following two cases is relevant:

1. If the outside option is binding $(v \geq \underline{v}(\gamma))$, the limited liability and competition effects operate in the same direction, increasing lending and borrower effort, and reducing interest payments.

2. If the outside option is not binding $(v<\underline{v}(\gamma))$, then neither the limited liability nor the competition effects is operative. Lending and effort do not increase but the interest payments are higher.

The limited liability effect comes from the fact that, as $\tau$ falls, more wealth can be collaterlized and liability of the borrower for losses incurred is greater. The competition effect works through the outside option of the borrower.

When the borrower earns his outside option, this limited liability effect allows the lender to offer a larger loan. Since effort and capital are complements, expected output increases too. However, this will lead to a larger repayment being demanded. Whether the interest rate $r / x$ increases or not is unclear a priori. ${ }^{13}$ This appears to be the case that De Soto (2000) has in mind. This limited liability effect is further reinforced by a competition effect which operates

\footnotetext{
${ }^{13} \mathrm{~A}$ rise in $w$ leads to a greater loan size and effort (which means that the gap between $r$ and $c$ shrinks). These effects tend to reduce $r / x$. But there is a direct increase in $r$ since so long as the limited liability constraint binds, the lender charges $w(1-\tau)$ in both states of the world. Because of diminishing returns with respect to $x$, as $w$ increases the loan size increases at a diminishing rate and eventually becomes constant when $w$ becomes very high, and $x$ equals the first-best. Formally, we find for the case $\underline{v}<v<\bar{v}$ that:

$$
\frac{\partial(r / x)}{\partial v}=-\left[p q-\gamma g-f-u+(1-p)\left\{\gamma g \frac{1}{p^{\prime} q} \Psi^{-1}-(1-\tau) w\right\}\right] \frac{\Psi q p^{\prime}}{g^{2} q^{\prime} p^{2}}
$$

where $\Psi \equiv\left(q^{\prime} p^{\prime}\right)^{2} /\left(q q^{\prime \prime} p p^{\prime \prime}\right)$ which is positive as both $p(\cdot)$ and $q(\cdot)$ are monotonically increasing and concave. Since $p q-\gamma g(v, \gamma)-f(v)-u=S(v, \gamma)>0$ and $\gamma g(v, \gamma)>(1-\tau) w$ when $v \in(\underline{v}, \bar{v})$, a sufficient condition for $r / x$ to be decreasing for all $v \in(\underline{v}, \bar{v})$ is $\Psi^{-1}>p^{\prime} q$ along the equilibrium path. An alternative sufficient condition for $r / x$ to be decreasing is that $S(v, \gamma)>v$. To see this recall $u+(1-\tau) w=v$. We know that $S(v, \gamma)>\underline{v}$ (see proof of Proposition 5). By continuitity $S(v, \gamma)>v$ holds for $v$ close to $\underline{v}$. At the first-best there is no change in $r / x$ as $w$ goes up.
} 
because the outside option, $\bar{u}((1-\tau) w, \bar{\gamma})$, also increases. This also increases lending and expected output.

If the borrower earns an "efficiency utility" which exceeds his outside option, things are different. Improving property rights now merely increases the power of the lender who can force the borrower to put up more of his wealth as collateral and pay a higher interest rate. Thus the limited liability effect constitutes a purely redistributive gain to the lender with no improvement for the borrower. This resonates with a point that is frequently made about informal contracting arrangements, namely that prevailing subsistence norms can be undermined by the formal legal system (see, for example, Bardhan, 2007). There is no competition effect in this case either as long as the borrower's utility continues to exceed that option. Although of course if the outside option improves sufficiently, the borrower flips into the case discussed in the previous paragraph. ${ }^{14}$

\subsection{Implications for Welfare}

To evaluate welfare, we need to take a stance on the weight that is attached to the utility of borrowers and lenders. We consider a policy objective which allows the weight on the welfare of borrowers and lenders to vary and use $\lambda$ to denote the relative weight on the welfare of borrowers:

$$
W(\tau ; \lambda)=(\lambda-1) u+S(u+(1-\tau) w, \gamma)
$$

We regard $\lambda \geq 1$, to be the natural case where there is a greater concern for the borrowers' welfare compared to the profits made by the lender.

\section{Proposition 5 When property rights improve}

1. If competition is intense enough, welfare is increasing for all values of $\lambda$. Moreover, borrowers and the efficient market lender are both strictly better off.

2. If competition is weak enough, the outside option is not binding and for $\lambda$ greater than or equal to one, welfare is decreasing.

The reasoning is clear. In the former case, the surplus generated by trading with any lender in the market increases, and with sufficient market competition, most of this surplus goes to borrowers who are therefore strictly better off. This result shows that with sufficient market competition, not only overall welfare (as defined above) goes up, but even the low cost lender benefits, that is, reducing $\tau$ creates a Pareto improvement. Below, we will look at the likely size of such effects. In the latter case, the more efficient lender has market power and poor borrowers

\footnotetext{
${ }^{14}$ This analysis assumes that competition in the credit market is exogenous. However, if improving property rights (lower $\tau$ ) raises profits in the monopolistic case, this could stimulate entry and move to a case where the outside option is binding, i.e. a flip from case 1 to case 2 in Proposition 4.
} 
receive an efficiency utility. When property rights to enable using assets as collateral improve, the lender is able to demand more wealth as collateral. This is a pure transfer - there is no efficiency improvement and total surplus is unchanged. Thus any welfare function which puts more weight (however small) on borrower welfare will register a welfare reduction when property rights improve.

These results emphasize the complementarity between market competition and market-supporting reforms to improve property rights. In the absence of competition, it may be optimal to keep property rights under-developed. Improving them only increases the prospect of exploitation of borrowers by lenders. The analysis identifies two factors which determine which case is more relevant: the wealth level of borrowers $(w)$, and the degree of competitiveness of markets $(\bar{\gamma}-\underline{\gamma})$. The efficiency gains should be largest if credit markets are sufficiently competitive and borrowers are neither too rich nor too poor. It is when credit markets are monopolistic and borrowers are poor, that reforming property rights will have little impact on efficiency but lenders will gain at the expense of borrowers.

\section{Application}

The typical approach in the existing applied literature has been to assess the effects of property rights improvements by regressing measures of loan size, interest rates and productivity on improvements in property rights (see, for example, Field and Torero, 2008 and Galiani and Schargrodsky, 2010). Proposition 4 provides a theoretical underpinning for this. However, even in cases of a clearly identified exogenous policy change, interpreting the magnitudes is likely to be context specific.

The model emphasizes three potentially important sources of heterogeneity that would be difficult to account for in such an exercise. First, the de Soto effect is likely to depend on the degree of competition in the credit market. This emerges immediately from the proposition above since competition determines whether the outside option is binding. Second, the comparative static results above are local, i.e. for a small change in $\tau$. But the starting point may matter a lot - a large change in property rights, for example, could lead to a flip from case 2 to case 1 above and look quite different from a small change. Third, the effects described in the Proposition are for a specific wealth level. But we would expect which cases applies to depend on a borrower's wealth. Also, the size of the effect could depend on wealth.

This paper takes a somewhat different approach compared to the existing literature by generating quantitative predictions from estimated parameter values from data on Sri Lanka. ${ }^{15}$ This will allow us to get a feel for the empirical magnitude of the de Soto effect as predicted by the theory and how this depends on the context. We look at the quantitative predictions for three different wealth groups (low, medium, and high, based on percentiles in the data) and look at the

\footnotetext{
${ }^{15}$ We thank Suresh de Mel, David Mckenzie and Chris Woodruff for providing us with the data.
} 
impact of changing $\tau$ over the whole unit interval, i.e. over the full range over which the extent of collateralizability may vary. We then explore how the results vary depending on whether the outside option is binding. These allow the de Soto effect that we estimate to be both non-linear and heterogeneous.

\section{$5.1 \quad$ Strategy}

The returns from a project are given by $\pi=p(e) q(x)$. In order to parameterise the model we assume the functional forms $p(e)=e^{\alpha}$ and $g(x)=B x^{\beta}$ with $\alpha, \beta<1$. These give rise to the linear structural equation

$$
\log \pi=\log B+\alpha \log e+\beta \log x+\nu,
$$

where we take $\nu$ to be an additive error term. The equilibrium level of $e$ is endogenous and, for an entrepreneur who is not borrowing or borrowing under the first-best contract, determined by the first order condition $p^{\prime}(e) q(x)=1$. Our parametrization implies the structural equation

$$
\log e=\frac{1}{1-\alpha} \log (B \alpha)+\frac{\beta}{1-\alpha} \log x+\epsilon
$$

where again $\epsilon$ is taken to be an additive error term. ${ }^{16}$ Substituting (11) into (10) yields the reduced from equation:

$$
\log \pi=\phi_{1}+\phi_{2} \log x+\nu+\alpha \varepsilon
$$

where $\phi_{1}=\frac{1}{1-\alpha} \log B+\frac{\alpha}{1-\alpha} \log \alpha$ and $\phi_{2}=\frac{\beta}{1-\alpha}$.

We estimate the parameters $\phi_{1}$ and $\phi_{2}$ by running a regression of this reduced from equation (see next section). We calibrate $\alpha$ by noting that $p(e)$ is the probability of non-default and choosing $\alpha$ such that the average non-default probability is equal to the empirical fraction of non-defaulted loans in our data. Given estimates of $\phi_{1}, \phi_{2}$ and $\alpha$, we are able to back out estimates of both $B$ and $\beta$.

\subsection{Data}

To derive estimates of the key parameters, we use data from a study of Sri Lankan microenterprises by De Mel, McKenzie, and Woodruff (2008) (MMW hereafter). They surveyed 408 microenterprises ${ }^{17}$ in the three southern and southwestern districts Kalutara, Galle, and Matara. The survey was conducted on a quarterly basis from March 2005 through March 2007 and collected, among other things, data on the amount of invested capital in Sri Lankan rupees (LKR), monthly profits, outstanding loan sizes and interest rates paid on those, and weekly working

\footnotetext{
${ }^{16}$ We use the marginal cost of effort as the numeraire throughout.

${ }^{17}$ This refers to the sample of enterprises which where not affected by the 2004 tsunami.
} 
hours. ${ }^{18}$ The study also provides estimates of the hourly wages. All currency units are deflated by the Sri Lanka Consumers' Price Index to reflect April 2005 price levels. A key innovation of the study is to generate shocks to the capital stock by randomly providing grants. This enables consistent estimation of the parameters in equation (12) by instrumenting for the capital stock with experimentally provided grants.

We use their data to construct a measure of effort as the ratio of the weekly working hours over the maximum weekly working hours reported in their dataset, which is 110. (Hence $e$ is bounded between 0 and 1.) At baseline the median hours worked by those who are borrowing is 56.0 , implying a median effort $e^{m}=0.509$. The median rate of loans at risk across Sri Lankan microfinance institutions reporting in 2005 on MixMarket.org was $5 \% .{ }^{19}$ Using this fact, we estimate $\hat{\alpha}=\log (0.95) / \log (0.509)=0.076 .^{20}$

Consistent with the exposition in the previous section, we normalize all currency units with the marginal cost of effort. A measure of the marginal cost of effort is the wage which would be earned at full effort (i.e. $e=1$ ) over the life span of the project, which we assume to be 12 months. ${ }^{21}$ We use $8 \mathrm{LKR} / \mathrm{h}$ for the quantitative estimates, which yields a marginal cost of effort of $45760 \mathrm{LKR}^{22}$ Below, we will assess the robustness of our findings to the alternative wages of $5 \mathrm{LKR} / \mathrm{h}$ or $10 \mathrm{LKR} / \mathrm{h}$ and for alternative time horizons of 6 and 24 months.

$$
<<\text { Table I about here }>>
$$

We use the data from MMW to estimate the linear structural equation (12) and obtain estimates $\hat{\phi}_{1}$ and $\hat{\phi}_{2}$. Column 1 of Table I presents estimation results for a regression of log of monthly (normalized) profits on a constant and the log of (normalized) capital. We instrument for the capital stock with the value of the experimentally provided money or inventory, as do MMW. We obtain estimates for the constant of -2.089 (s.e. $=0.097$ ) and for $\phi_{2}$ of 0.570 (s.e. $=0.115$ ). Note that we use monthly profits as outcome variable, rather than yearly profits. Hence our estimate of $\phi_{1}$ is $\hat{\phi}_{1}=-2.089+\log 12=0.396$. We back out $\beta$ and $B$ from $\hat{\phi}_{1}$ and $\hat{\phi}_{2}$ as $\hat{B}=\exp \left((1-\hat{\alpha}) \hat{\phi}_{1}-\hat{\alpha} \log \hat{\alpha}\right)=1.754$ and $\hat{\beta}=(1-\hat{\alpha}) \hat{\phi}_{2}=0.526$.

Equation (11) holds under the assumption that $r=c$, i.e. the individual is not borrowing or borrowing under the first best. We check the robustness of our results by deriving our estimates

\footnotetext{
${ }^{18}$ For more details check MMW (2008), Section III.

${ }^{19}$ See http://www. mixmarket.org/mfi/country/SriLanka.

${ }^{20}$ Alternatively we can choose $\alpha$ to match the average frequency of loans at risk across microfinance institutions, which might be about $8 \%$ according to MixMarket.org. Then we would find our estimate $\hat{\alpha}$ from $\int f_{e} e^{\hat{\alpha}} d e=0.92$. This yields a fairly similar estimate of $\hat{\alpha}=0.063$. Below, we will assess the robustness of our results to the alternative parametrisations $\alpha=0.026$ and $\alpha=0.126$.

${ }^{21}$ We set $w=\eta$, i.e. there is a perfectly elastic supply of labor at a wage equal to the marginal cost of effort. MMW (pp. 1352-1353) provides two estimates for the hourly wage rate. One estimate ranges from 0 to 9 LKR/hour for different groups, the other ranges from 7.9 to 17.3. The latter is almost surely an overestimate of the wage rate.

${ }^{22}$ We calculate the marginal cost of effort as the hourly wage rate multiplied by 110 to obtain a full-effort weekly wage rate, multiplied by 52 to get the cost of effort 1 exerted over the span of the project.
} 
from this sub-sample of the population alone. In column 2 of Table I we present results from a regression which is equivalent to the regression in column 1, but where we restrict the sample to individuals who do not borrow at baseline. It is reassuring to see that the coefficient estimates are virtually identical to those obtained from the full sample.

We will present predictions on the equilibrium contracts for three wealth levels, which correspond to the 5th, 25th and 50th percentiles of the empirical wealth distribution. Figure I presents a histogram of the wealth distribution and the three percentiles. The 5th, 25th and 50th percentiles are $\{4989,35137,81915\}$, and normalized by the marginal cost of effort these are $\{0.1090,0.7679,1.7901\}$.

$$
<<\text { Figure I about here }>>
$$

For our estimate of $\gamma$ we use a nominal interest rate of $8 \%$ which is the average of two yearly deposit rates published by the central bank for April 2005. ${ }^{23}$

\subsection{Baseline Results}

The baseline quantitative estimates of the de Soto effect are for the case where the outside option is autarky, i.e. $\bar{u}=0$, corresponding to the case of a monopolistic lender. Figure II shows the predicted interest rate $(r / x-1) / 100$, the leverage ratio $(x / w)$, and the borrower's profits, $p(e)(q(x)-r)-(1-p(e)) c$, as a function of the extent to which capital can be collateralized as measured by $(1-\tau)$. They are shown for the three wealth levels specified above.

$$
<<\text { Figure II about here }>>
$$

Quantitative estimates of the de Soto effect are represented by movements along the horizontal axis in Figure II. It is the slope of these lines which represent the response to improvements in property rights protection.

The predicted interest rates for the case without competition are shown in the left hand panel. These are greater than $80 \%$.

They generally fall with improvements in property rights and we see that for higher wealth groups, the interest rate is lower for almost all values of $\tau$. For the lowest wealth group these increase from around $180 \%$ to nearly $200 \%$ for high $\tau$ but fall thereafter. While such rates are very high, they are close to what respondents in these data report when asked at which rate they could borrow from a moneylender. Those 54 respondents in the data who do not borrow from

\footnotetext{
${ }^{23}$ The data is downloadable at http://www.cbsl.gov.lk/htm/english/08_stat/s_5.html.
} 
a formal lender state an average moneylender interest rate of $182 \%{ }^{24}$ The increasing range in the left hand panel of Figure II corresponds to the case in the theoretical model where the borrower is worse off from improvements in property rights as these make it easier for the lender to extract surplus from the borrower. The reduction in interest rates for the middle and high wealth groups are substantial from above $180 \%$ to around $90 \%$. These remain high principally because competition is weak in this case.

The amount borrowed increases in all three wealth groups over most of the range. However, the increases are modest for the middle and low wealth groups with leverage relative to wealth only rising from about $16 \%$ to $26 \%$ for the high wealth group. The poor will only borrow more when property rights are sufficiently good. Their leverage ratio rises from around 260\% to $310 \%$. The case where the amount borrowed remains constant corresponds again to the range of $\tau$ in which improvements in property rights only lead to an increased extraction of surplus by the lender.

Average realized profits increase with improvements in property rights throughout the range of $\tau$ for the high and middle wealth groups. For the low wealth groups improved property rights lead to higher profits only at low values of $\tau$. Increased profits reflect a compensation for the higher exerted effort. At higher levels of $\tau$ profits are falling for the low wealth group as property rights improve since this allows a monopolistic lender to extract more surplus.

Our assumption of $\bar{u}=0$ makes Figure II essentially a partial equilibrium analysis. We now consider what happens when we allow the outside option to improve as $\tau$ changes. This requires that there is sufficient competition in the credit market.

$$
<<\text { Figure III about here }>>
$$

In Figure III, we assume that the competitor also has a cost of funds of $8 \%$ and is subject to the same $\tau$. Now as we change $\tau$, the outside option of the borrower changes endogenously. The three panels report the same variables as Figure II and the comparison between Figures II and III demonstrates the effect of increased competition.

In Figure III, improving property rights is welfare improving throughout the whole range of $\tau$. Moreover, the level of interest rates is dramatically lower compared to Figure II. Even when property rights are very poor, interest rates are close to 50 percentage points below the interest rate with perfect property rights in the absence of competition. Increases in leverage are now very modest suggesting that property rights in this setting are not likely to be associated with large increases in the amount borrowed relative to wealth for any group. Thus, the primary effect is coming through higher effort which also drives the effect in the third panel where average profits rise with improvements in property rights. ${ }^{25}$

\footnotetext{
${ }^{24}$ In this we drop one outlier, who states his interest rate as a daily payment of $3 \%$, which amounts to a yearly interest rate of around $4848172 \%$.

${ }^{25}$ This is consistent with MMW's observation that there are significant changes in hours work when they exogenously vary the amount of capital available to enterprises.
} 
The above results suggest that the effects of having competition in the credit market can be dramatic. Also, the effects of property rights reform seem to be strongly complementary with the degree of competitiveness of credit markets. This suggests the potentially high returns from complementary reforms aimed at enhancing competition in the credit market, and improving property rights as opposed to focusing on the latter in isolation. These results also illustrate that the de Soto effect is indeed heterogeneous by wealth and that an average effect could be quite misleading. The effect of changing $\tau$ is also non-linear so that the measured effect will depend on the starting point for $\tau$.

\subsection{Welfare}

We now assess the magnitude of the welfare gains from improving the collateralizability of wealth. The main difference between these effects and those in the previous section lie in the fact that the cost of effort is taken into account. The results are in Figure IV where utility is measured as a proportion of the value of the labour endowment.

The dashed line in Figure IV represents total surplus for the case where competition is absent, corresponding to Figure II. The solid black line is the utility of the borrower in this case and corresponds to the second part of Proposition 5. It is no surprise therefore that borrower welfare falls. There is a $5 \%$ reduction in the borrowers' utility while lenders' profits increase by around $5 \%$ to $10 \%$ of the value of the average annual labor endowment. ${ }^{26}$ While total surplus increases as $\tau$ falls for low initial values of $\tau$, the distributional weight matters; even a slight preference for borrower over lender welfare makes it unlikely that improving property rights will raise welfare.

$$
<<\text { Figure IV about here }>>
$$

The top line in Figure IV shows the borrowers' utility in the case of high competition. This corresponds to the first part of Proposition 5 so we know that welfare is higher. However, the figure appears to suggest a modest $2 \%$ gain in welfare even if property rights move from the worst possibility to the very best.

This small gain in welfare appears puzzling at first sight given the significant reduction in the interest rate and increase in profits shown in Figure II. However, the reason that this does not translate into a large utility gain is due to the fact that improvements in property rights are inducing an increase in effort rather than an increase in the amount borrowed. Our welfare calculations take into account the utility cost of increased effort. Whether policy makers care about this in practice is moot; it may be that the productivity gains are the primary focus of

\footnotetext{
${ }^{26}$ The lenders profits are the difference between total surplus and the borrowers' utility, i.e. between the dashed green line and the solid black line.
} 
any policy evaluation. But, as we show here, productivity can increase without there being a large utility gain. One advantage of working with a specified theoretical framework lies in being able to bring this out.

\subsection{Robustness}

\subsubsection{Model Fit}

We are using a very specific model to predict the effects of property rights improvements on credit contracts. The credibility of the approach is enhanced to the extent that its testable predictions can be verified in the data. Here we compare the empirical relationship between the loan size and the borrower's wealth to the model's predictions. We expect the link between the loan size and borrower wealth to depend on the level of competition, which we do not observe. However, the baseline survey conducted by MMW asked: 'Suppose you wanted to borrow money from a moneylender. What is the maximum amount you would be allowed to borrow?' It is reasonable to assume that the question was interpreted as asking 'Suppose you could only borrow from a moneylender, what is the maximum amount you could borrow?' Thus, we have data on hypothetical loans from a moneylender under monopolistic competition. Plotting this variable against assets, we find that the relationship is flat at a low level of wealth and then increasing. ${ }^{27}$ Qualitatively this is what we would expect under monopolistic competition.

We can also use the hypothetical loan size given in answer to this question to check whether the relationship between loan size and wealth is quantitatively consistent with the model's predictions. In the monopolistic case, the model predicts (for any parametrisation) that the amount borrowed is independent of the borrower's wealth for wealth when $(1-\tau) w<\underline{v}$. Our calibration sets $\underline{v}=0.0416 .^{28}$ We do not know the value of $\tau$ which makes sense for Sri Lanka, but assume that it is, say, 0.8. Then any individual with (normalised) wealth below $0.0416 /(1-0.8)=0.208$, corresponding to a non-normalised wealth of $9518 \mathrm{LKR}$, would receive an efficiency credit contract. ${ }^{29}$ We can test the prediction that below this value of wealth, the loan size is independent of wealth by regressing the hypothetical loan size given in answer to the question from the baseline survey above, on wealth using the sample of individuals with wealth levels below 9518 LKR. This yields a slope coefficient of 0.261 (s.e. $=1.687$, p-value $=0.878$ ) with a constant of 24486 $($ s.e. $=8089$, confidence interval $[8136,40836]){ }^{30}$ The slope coefficient is not significant at conventional levels. Furthermore, in the low wealth range the model predicts a (normalised) loan

\footnotetext{
${ }^{27}$ Supplementary Figure I presents a scatterplot of this data and the value of the business assets, which is our measure of wealth. It presents data for the below median wealth groups. In particular it presents data for individuals with wealth below 50000 LKR, i.e. roughly one year of labour endowment. We focus on the lower wealth range since the model predicts a flat relation for wealth below $9518 \mathrm{LKR}$. This would otherwise be difficult to see. The figure as well excludes individuals with a stated hypothetical annual interest rate greater than $1000 \%$.

${ }^{28}$ This can as well be seen in Figure II. For the lowest wealth group, with normalised wealth of 0.1090 , we have an efficiency loan contract for effective wealth of about $0.4 \times 0.1090$.

${ }^{29}$ This assumes $u=0$.

${ }^{30}$ The sample size is 42 . We exclude individuals with a stated hypothetical annual interest rate over $1000 \%$.
} 
size of $x_{0}=0.2888$, or non-normalised value of 13215 LKR. This is well within the confidence interval of the constant term of this regression.

For wealth levels such that $\underline{v}<v<\bar{v}$ the model's prediction is not linear in general. However, with our parametrisation we find the loan size to be $x=v^{\frac{\alpha}{1-\beta}} \cdot\left((\alpha /(1-\alpha))^{\alpha} B \beta / \gamma\right)^{\frac{1}{1-\beta}}$. Taking logs, inserting our parameter estimates and assuming $\tau=0.8$ this predicts the linear relationship $\log x=-0.99+0.1604 \log w$. In order to test this prediction we regress $\log x$ on $\log w$ and a constant, using the sample of individuals with wealth levels such that $\underline{v} /(1-0.8)<w<\bar{v} /(1-$ 0.8). We now find a slope coefficient of 0.213 (s.e. $=0.081$, confidence interval $[0.05,0.37]$ ) and a constant of -1.051 (s.e. $=0.067$, confidence interval $[-1.18,-0.92]){ }^{31}$ The model's estimates of the intercept and slope coefficient are both inside these fairly tight confidence bounds. ${ }^{32}$

\subsubsection{Sensitivity to parameter estimates}

We now discuss the robustness of the findings to perturbations in $\alpha, \beta, B$, the time horizon, and wage level. To calculate $95 \%$ confidence bounds on $\beta$ and $B$, we calculate the $\beta$ and $B$ implied by the limits of the $95 \%$ confidence interval of the estimates of $\phi_{1}$ and $\phi_{2} \cdot{ }^{33}$ These correspond to $[0.318,0.734]$ and $[1.470,2.094]$, respectively. Further we consider how the results would change if we had used instead $\alpha=0.026$ or $\alpha=0.126$, a time horizon of 6 or 24 months, and a wage level of $5 \mathrm{LKR} /$ hour or $10 \mathrm{LKR} /$ hour.

The detailed results are presented in a series of figures available in the Online Appendix. Generally speaking, our results do not appear to be particularly sensitive to wide variations in the parameters with the possible exception of the time horizon. Had we assumed a 2 year time horizon, we would have concluded that property rights improvements are detrimental for a wider range of high $\tau$ and they would always be detrimental for the lowest wealth group. Conversely, had we assumed a 6 months time horizon we would have concluded that property rights improvements are beneficial for a wider range of initial $\tau$. While the magnitudes of the results are different across specifications, the core welfare conclusions remain the same.

\subsubsection{Estimates based on data from Ghana}

We also assess the robustness of the findings by looking at data from Ghana using a similar study of microenterprises to that in Sri Lanka from Fafchamps, McKenzie, Quinn, and Woodruff (2011),

\footnotetext{
${ }^{31}$ The sample size is 361 . We exclude individuals with a stated hypothetical annual interest rate over $1000 \%$.

${ }^{32}$ Another testable implication of the modeling of the credit constraint in the paper is that effort is closely tied to the probability of success of the project, and so we would expect variation in profits to be negatively related to effort (because the probability distribution is binary so that the variance is an increasing function of $p(e)(1-p(e))$, which is increasing in $p(e)$ for $p(e)>\frac{1}{2}$, which in turn is true even for very low values of $e$ given the estimate we use of $\alpha$ ). We regressed the standard deviation of $\log$ (profits) within firm across the 9 waves of data which MMW use on the mean effort during that time, i.e. mean of hours worked devided by 110 . We use all observations which are covered both in the first and last wave $(\mathrm{N}=320)$. This simple regression gives a slope coefficient of -0.147 (s.e. $=0.073$, p-value $=0.045$ ).

${ }^{33}$ These are $[-2.280,-1.898]$ and $[0.345,0.794]$, respectively.
} 
henceforth FMQW. ${ }^{34}$ We essentially use the same strategy as in the baseline results. The nonrepayment probability for Ghanian microfinance institutions is reported to be at most $3.8 \%{ }^{35}$ The study by FMQW reports a mean of 57.9 weakly working hours, implying $\bar{e}_{\text {Ghana }}=0.526$ and $\hat{\alpha}_{\text {Ghana }}=\log 0.962 / \log 0.526=0.060$. The median wage for paid employees in urban areas (which is where the FMQW study was undertaken) is 1.33 cedi/hour for males and 1 cedi/hour for females. ${ }^{36}$ Using a wage rate of 1 cedi/hour we have $\eta_{\text {Ghana }}=5720$. The results from an instrumental variable regression of monthly profits (in Ghanian cedi) on a constant and the capital invested (in Ghanian cedi) are shown in column 3 of Table I. As in the case of the Sri Lankan study we instrument for the capital stock with experimentally provided grants. The coefficient estimate of the elasticity of profits with respect to capital is surprisingly close to the equivalent coefficient estimate in the Sri Lankan data. The regression reported in column 3 of Table I uses non-normalized values. Correcting for this and the fact that profits are measured monthly (rather than yearly) we find $\hat{\phi}_{1, \text { Ghana }}=1.216+\log 12+\left(\hat{\phi}_{2, \text { Ghana }}-1\right) \log 5720=-0.053$, which implies $\hat{B}_{\text {Ghana }}=\exp \left(\left(1-\hat{\alpha}_{\text {Ghana }}\right) \hat{\phi}_{1, \text { Ghana }}-\hat{\alpha}_{\text {Ghana }} \log \hat{\alpha}_{\text {Ghana }}\right)=1.127$. Further we find $\hat{\beta}_{\text {Ghana }}=\left(1-\hat{\alpha}_{\text {Ghana }}\right) \hat{\phi}_{2, \text { Ghana }}=0.532$. The values for $\alpha$ and $\beta$ are strikingly close to the values we had found for Sri Lanka, while the technology parameter $B$ is somewhat lower in Sri Lanka. ${ }^{37}$ This suggests that the underlying production technology might actually be quite similar across these two countries.

As in Sri Lanka, we do not have good data on household wealth in Ghana. We will instead use data on business capital provided to us by David McKenzie and comparable to the data used from Sri Lanka. The the 33rd, 50th and 66th percentile of the distribution of business capital are $\{5.78,208,862\}$, and their normalized values are $\{0.0010,0.0364,0.1507\}$. For the sake of comparison, note that for the Sri Lankan data, the corresponding normalized values of the $33 \mathrm{rd}, 50 \mathrm{th}$ and $66 \mathrm{th}$ wealth percentile are $\{0.4484,1.7901,2.6754\} .{ }^{38}$ Hence the percentiles of the Ghana data are considerable lower than their corresponding values for Sri Lanka. This is consistent with the average per capita income in Ghana being around a third of the Sri Lankan average per capita income and the technology parameter $B$ also being lower for Ghana.

\section{$<<$ Figure V about here $>>$}

Figure Va and Vb present the model's predictions in the non-competitve and competitive case for Ghana, corresponding to Figures II and III which use Sri Lankan data, respectively. The

\footnotetext{
${ }^{34}$ We grateful to David McKenzie for providing us with the results that we needed for this robustness check.

${ }^{35}$ Data from http: www.mixmarket.org/mfi/sat/data.

${ }^{36}$ This data is from the 'Ghana Living Standards Survey, Fifth Round' and was provided to us by David McKenzie.

${ }^{37}$ Note that the technology parameter is normalised by the value of a year's labour endowment. This is likely to be different between the two countries.

${ }^{38}$ Recall, however, that in the results presented for Sri Lanka above, we depicted the 5 th, 25 th and 50 th wealth percentile.
} 
main difference to the Sri Lankan case is that a substantially bigger group of individuals would not benefit from marginal improvements in property rights. In particular, an individual at the 33rd percentile of the wealth distribution would be worse off from an improvement in property rights, irrespective of the initial level of property rights protection. This point would only be strengthened if we considered individuals at the 5 th or 25 th percentile of the wealth distribution, as we did in the Sri Lankan case. Similarly, in the competitive case we expect interest rates to fall less with an improvement of property rights. Hence the observation that the wealth distribution is rather different leads us expect different effects of improving property rights in Ghana compared to Sri Lanka. This is true even though the core parameters are similar and essentially reflects that individuals with low wealth comprising a larger fraction of the population.

\section{Extensions}

\subsection{Adding a Fixed Cost}

Adding a fixed cost to undertaking a project seems intuitive, and is a standard element in most theoretical models of borrowing constraints and poverty traps (e.g., the occupational choice literature surveyed in Banerjee, 2003). However, we did not include it in our basic model to focus on de Soto's argument that the poor may have wealth, but due to institutional failures, their wealth becomes "dead capital".

In standard models of poverty traps, anything that improves the operation of credit markets will improve efficiency. However, the focus on the literature to date has been on the role of wealth inequality and redistributive policies. Our analysis suggests a distinction between a wealth-constrained and an institution-constrained economy. If wealth levels are low, then even as $\tau \rightarrow 0$, markets remain second best since there is insufficient collateral to sustain the first best. In this economy borrowers are genuinely wealth constrained. This is to be contrasted with a situation where the problem is lack of development of the legal system. This is characterized by a situation in which $w \geq \underline{\gamma} x^{*}(\underline{\gamma})$ while $\tau$ is strictly positive. For this case, for high enough $\tau$ the first-best is not achieved, and the economy is institution-constrained. In the latter environment, the policy implications are obvious, but in the former environment institutional reform alone will not make a huge difference.

We now explore these ideas further and their implications for the quantitative estimates of the de Soto effect by considering a production function where a project requires a fixed cost of $F{ }^{39}$ Naturally, such a cost reduces the net surplus and lowers the likelihood of a gainful exchange between the lender and the borrower. At the same time, net surplus is increasing in $w$ in the second best and therefore, the higher the wealth of the borrower, the more likely a loan will be given for a given level of $F$. We show:

\footnotetext{
${ }^{39}$ Adding a fixed cost is equivalent to having an outside option of the lender.
} 
Proposition 6 Suppose the project requires a fixed cost $F \in(S(\underline{v})-\underline{v}, S(\underline{v}))$ that a lender incurs to make any non-negative loan to the borrower. Then there is a critical wealth level $\underline{w}(F, u ; \gamma) \geq 0$ such that a lender would provide a positive loan if and only if the borrower has wealth $w>\underline{w}(F, u ; \gamma)$. The threshold $\underline{w}(F, u ; \gamma)$ is non-decreasing in $F$ and $u$.

Figure VI shows how the model's predictions for credit contracts and profits change when a project requires a fixed cost. For illustrative purposes, we have assumed a fixed cost equal to one quarter of the borrower's labour endowment. ${ }^{40}$ Figure VIa displays the results for the monopolistic case, corresponding to Figure II. In this case the effect of the fixed cost is simply to exclude individuals with collateralizable wealth below $\underline{w}(F, u ; \gamma)$ from access to loans. The loan contracts $(r, c, x)$ for individuals who do receive a credit are unchanged, where we denote $x$ net of the fixed cost. However, the gross loan size (including the fixed cost) increases, it is $x+F$, and hence the interest rate is lower and the leverage ratio higher.

Figure VIb presents how our results change for the monopolistic case, corresponding to Figure III. We see how the same individuals who are excluded from access to credit remain so with competition. Compared to the case without a fixed cost, the predicted interest rate and leverage ratio increase. The interest rate increases, since the outside option is lower, as a second lender can no longer offer $S(v)$, but $S(v)-F$. The leverage ratio increases since the gross loan size increases (despite $x$ decreasing). The borrower's profits are lower again because the outside option decreases, reducing $x$ and $e$.

\section{$<<$ Figure VI about here $>>$}

One of the main conclusions of our calibration exercise - the complementarity of property rights and credit market reforms - is unaffected by the introduction of a fixed cost. Property rights reforms now have an extensive margin effect. The size of this effect in aggregate will depend on the wealth distribution and how many potential borrowers there are close to threshold where borrowers who were receiving no credit before will gain access to credit after such a reform. This effect is larger with competition since, in the absence of competition, the lender will extract the borrower's surplus. Second, we find that the increase in the borrower's profits when $\tau$ falls is again markedly higher (especially for the low wealth group and for high values of $\tau$ ) with competitive credit markets compared to a monopolistic credit market. In fact this conclusion is strengthened when introducing a fixed cost. Similarly, the decrease in interest rates induced by property rights reforms is considerably stronger in a competitive credit market. When it comes to welfare, it is now possible to get a significant extensive margin effect when there is

\footnotetext{
${ }^{40}$ In this illustrative example we choose $F$ deliberately such that almost all individuals who receive an efficiency utility in the case of no fixed cost would receive no credit in the case with a fixed cost. Hence property rights reforms cannot be detrimental.
} 
competition. This is particularly pronounced for poor borrowers who are excluded altogether from the credit market when $\tau$ is high.

So introducing a non-convexity into the production technology does have a striking impact and could therefore be important in assessing the empirical size of the de Soto effect. The nonlinearities as $\tau$ changes are particularly striking. As in the baseline model, the effects remain heterogeneous by wealth group and according to the level of competition. The assessment of welfare gains will now depend on the underlying wealth distribution and the fraction of potential borrowers who are helped by the reform.

\subsection{Alternative Dimensions of Competition}

The basic model assumes that all credit transactions take place in a common, although imperfect, contracting environment. But an important feature of economies where property rights are poorly developed is the presence of relationship-based or informal transactions which are not enforced by formal contracts. These informal lenders often coexist with formal lenders despite having higher cost of capital because of their access to better local information and the ability to use non-pecuniary sanctions (see Banerjee, 2003 for a review). Improvements in the formal contracting environment is expected to shrink the size of the informal sector and this would be another dimension of the de Soto effect. Informal lenders also add another dimension of competition - formal lenders may have a lower cost of capital while informal lenders might have lower transactions costs.

To see this formally, suppose that the collateral value of a borrower's assets is match-specific, i.e. depends on the lender with whom he deals with. We assume that there are two types of lenders: informal lenders (e.g., who belong to the same ethnic group or live in the same village) and formal lenders. The collateralizable value of wealth when dealing with an informal lenders is $(1-\underline{\tau}) w$, but to formal lenders it is $(1-\bar{\tau}) w$ where $\bar{\tau}>\underline{\tau}$ reflecting the greater ability of an informal lender to seize collateral in the event of a default. Also, assume that the opportunity cost of capital for informal lenders is $\bar{\gamma}$ whereas for the efficient formal lender, it is $\underline{\gamma}$, so that there is a trade-off.

This two-dimensional heterogeneity on the lending side allows a richer market equilibrium where borrowers match with either a formal or an informal lender. Informality survives in market equilibrium if and only if for some borrower with wealth level $w>0$ :

$$
\bar{u}((1-\underline{\tau}) w, \bar{\gamma}) \geq \bar{u}((1-\bar{\tau}) w, \underline{\gamma})
$$

where $\bar{u}$ solves $u=S(w(1-\tau)+u, \gamma)$. If this condition holds then it must be for wealth levels 
that are neither too high nor too low. ${ }^{41}$ Consider a value of $w$ such that

$$
\bar{u}((1-\underline{\tau}) w, \bar{\gamma})=\bar{u}((1-\bar{\tau}) w, \underline{\gamma})
$$

Such a borrower is indifferent between using the informal sector and an inefficient formal sector lender. If there is a reduction of $\bar{\tau}$, i.e. an improvement in formal property rights, then this marginal borrower strictly prefers using the formal sector. For borrowers who switch to the formal sector, effort and loan size will increase. Even for borrowers who continue to borrow from the informal sector, their outside option improves, and this would increase effort and loan size. If $\bar{\tau}$ goes down sufficiently (e.g., equals $\underline{\tau}$ ) then the informal sector will disappear.

\section{Concluding Comments}

This paper has developed a model to explore the incentive effects associated with extending the use of collateral to support trade in credit markets. The model has been applied by using parameters estimated from Sri Lankan data. This has allowed us to explore both non-linearities and heterogeneity in the effects. We have highlighted how gains vary by initial wealth, the extent of competition in the credit market and the initial level of effective property rights.

Both the theory and the evidence support the possibility of significant effects on interest rates and profits from improving property rights. However, these appear to come predominantly from increases in effort rather than increased levels of borrowing. In other words, the model predicts that moral hazard will be reduced. This explains why an increase in measurable output may not be the same as an increase in economic welfare which would factor in the cost of effort. This conclusion does seem robust to varying the parametrizations. However, if we add a fixed cost to the technology, then an improvement in property rights can have an extensive margin effect with significant numbers of borrowers now having access to credit who were previously excluded. Whether this effect is large or small depends on the wealth distribution.

In this paper we looked at only one channel through which property rights affects productivity and with a somewhat specific model. There are several other potential channels through which improved property rights can affect productivity, such as, reducing expropriation risk, reducing the need to divert productive resources to protect property rights, and facilitating gains from trade through rental and sales of assets. ${ }^{42}$ From a methodological point of view, the analysis provides a framework which could be extended or modified to analyze the effects of these alternative channels. The analysis also provides a framework which should be useful in studying the impact

\footnotetext{
${ }^{41}$ To see this, recall that $S(\bar{v}, \gamma) \equiv S^{*}(\gamma)$ is decreasing in $\gamma$ and therefore, for $w$ such that $w(1-\bar{\tau})+$ $\bar{u}((1-\bar{\tau}) w, \bar{\gamma}) \geq \bar{v}$, the above condition cannot hold. Similarly, if $w=0$, then $\bar{u}(0, \bar{\gamma})<\bar{u}(0, \gamma)$ and once again, the above inequality cannot hold.

${ }^{42}$ See Besley and Ghatak (2009) for a discussion of these different mechanisms. In a fascinating study, Di Tella et al. (2007) look at the impact on beliefs. Galiani and Schargrodsky (2010) looks at possible dynamic effects due to wealth accumulation.
} 
of other policy initiatives in this area. We conjecture that our focus on market equilbrium effects in which features like the competitiveness of the credit market and the wealth distribution play important roles, are likely to be important considerations in determining outcomes in a wide variety of situations.

Another important direction for developing the approach is to consider a wider range of policy interventions in the credit market including measures aimed at increasing credit market competition or different forms of subsidy schemes. The framework could also be used to address a variety of on-going debates about the returns to micro-finance which is also aimed at reducing frictions in credit markets.

Overall, the analysis serves as reminder that, when it comes to policy reform in environments with many institutional failures, there are unlikely to be any magic bullets and policy reform needs to be assessed in light of the specific context and its features. ${ }^{43}$ Our paper also underscores the potentially important role of marrying theory with quantitative evaluation using estimates of structural parameters derived from experiments in the process of policy evaluation in this area.

\section{Appendix I: Proofs}

Proof of Proposition 1. The first best maximizes joint surplus:

$$
\max _{e \in[0, \bar{e}], x \in[0, \bar{x}]} p(e) q(x)-e-\gamma x
$$

Assumption 1 (i)-(iv) implies that an unique solution exists in the first best as the maximization problem is concave, well-behaved, and by standard arguments, a unique global maximum $\left(e^{*}, x^{*}\right)$ exists. By Assumption 1 (iii), $e^{*} \in(0, \bar{e})$ and $x^{*} \in(0, \bar{x})$. The first best $\left(x^{*}, e^{*}\right)$ is the solution to (1) and (2).

Note that $r=c$ is a necessary condition for the first best to be implemented. Suppose not, so that $r \neq c$ and yet, if possible, the first-best is implemented. Given $r \neq c$ it follows from the ICC that given $x^{*}$, an $e \neq e^{*}$ would be optimal for the borrower. This contradicts the first best being implemented. So $r=c$. Then the lender's optimization problem is to maximize $c-\gamma x^{*}$ subject to the LLC

$$
(1-\tau) w \geq c
$$

and the PC given by

$$
p\left(e^{*}\right) q\left(x^{*}\right)-e^{*}-u \geq c .
$$

The lender will want to choose $c$ as high as possible, subject to the constraints. It is useful to rewrite $p\left(e^{*}\right) q\left(x^{*}\right)-e^{*}=S^{*}+\gamma x^{*}=\bar{v}$. If $(1-\tau) w \geq \bar{v}-u$, then the $\mathrm{PC}$ will be the binding

\footnotetext{
${ }^{43}$ This is a theme of a strand of the recent development policy literature - see, for example, Rodrik (2008).
} 
constraint. Hence $c$ will be set to $S^{*}-u+\gamma x^{*}$, the lender will get the first-best surplus minus the reservation payoff of the borrower, and he cannot do better than that.

Proof of Proposition 2. The proof of Proposition 2 proceeds in 4 steps.

Step 1: (i) At the optimal contract $r \geq c$. (ii) If $r>c$ under the optimal contract, then $c=(1-\tau) w$. (iii) If $c<(1-\tau) w$ under the optimal contract, then $r=c$ and effort is at the first-best level.

Proof of Step 1:

(i) Suppose not. Consider a small increase in $r$ to $r+d r$ and a small decrease in $c$ to $c+d c$ that keeps the borrower's payoff constant, so $p(e) d r+(1-p(e)) d c=0$. Hold $x$ constant. This contract is feasible as the LLC, $c \leq w(1-\tau)$ will be satisfied if it was before and the PC is satisfied by construction. The contract will decrease $e$ via the ICC. Using the envelope theorem we can ignore the effect of this change on the borrower's payoff via $e$. The change in the lender's payoff is given by

$$
p^{\prime}(e)(r-c) d e+p(e)(d r-d c)+d c=p^{\prime}(e)(r-c) d e
$$

as $p(e)(d r-d c)+d c=0$ from above. As $r-c<0$ by assumption and $d e<0$ this expression is positive and so the lender is better off, implying a contradiction.

(ii) Suppose not. Then it is possible to increase $c$ by a small amount (this is feasible as by assumption $c<(1-\tau) w)$ and decrease $r$ so as to keep the borrower's payoff constant. Effort will be higher due to the ICC. Furthermore, as $r>c$ by assumption the lender will be strictly better off, a contradiction.

(iii) Notice that, given the binding LLC, the statement " $r>c$ implies $c=(1-\tau) w$ " implies the statement "c< $(1-\tau) w$ implies $r \ngtr c$ ". Also by (i), $r>c$, and so $r \ngtr c$ is equivalent to $r=c$.

Step 2: For any $v<\bar{v}(\gamma)$, the optimal contract satisfies $c=(1-\tau) w$.

Proof of Step 2: Suppose it did not. Then by step 1(iii) the contract would implement the first best $\left(x^{*}, e^{*}\right)$. From the proof of proposition 1 we know that for any $v<\bar{v}(\gamma)$, when implementing the first best the LLC will be binding, yielding a contradiction.

Step 3: There exists $\underline{v}(\gamma)$ such that for $v \in[0, \underline{v}(\gamma))$, the optimal contract is characterized by $e=e_{0}<e^{*}(\gamma), x=x_{0}<x^{*}(\gamma), r=r_{0}>c=(1-\tau) w$.

Proof of Step 3: Suppose that for the optimal contract the PC does not bind. Using the binding LLC the optimal contracting problem can be written in the following modified form:

$$
\max _{\{x, e\}} p(e)\left(q(x)-\frac{1}{p^{\prime}(e)}\right)+(1-\tau) w-\gamma x .
$$

By Assumption 1 (v) the objective function is strictly concave. As a result this maximization problem is well-behaved, and by standard arguments, a unique global maximum $\left(e_{0}, x_{0}\right)$ exists. 
Further the objective function at $\left(e_{0}, x_{0}\right)$ is positive. The first-order necessary conditions for an interior optimum are:

$$
\begin{aligned}
& p^{\prime}\left(e_{0}(\gamma)\right) q\left(x_{0}(\gamma)\right)=1+\epsilon\left(e_{0}(\gamma)\right) \\
& p\left(e_{0}(\gamma)\right) q^{\prime}\left(x_{0}(\gamma)\right)=\gamma .
\end{aligned}
$$

Note that $\epsilon(e) \equiv-p^{\prime \prime}(e) p(e) /\left\{p^{\prime}(e)\right\}^{2}$ is strictly positive due to the strict concavity and strict monotonicity of $p(e)$, and is bounded and continuous for $e \in[0, \bar{e}]$. Given Assumption 1 (iii), therefore, the unique global maximum $\left(e_{0}, x_{0}\right)$ is an interior solution.

Next we show that $e_{0}<e^{*}(\gamma)$ and $x_{0}<x^{*}(\gamma)$. Write $(16)$ as $p^{\prime}(e) q(x)=a$, where $a \geq 1$. Note that when $a=1$, this is condition (1). It is easy to derive how the solution to the system of equations of $p^{\prime}(e) q(x)=a$ and (17), which is the same as (2), changes with $a$. We find $\frac{d e}{d a}=p q^{\prime \prime} /\left(p^{\prime \prime} q p q^{\prime \prime}-\left(p^{\prime} q^{2}\right)\right.$, where $\left(p^{\prime \prime} q p q^{\prime \prime}-\left(p^{\prime} q^{2}\right)>0\right.$ by the concavity of $p(e) q(x)$ and $q^{\prime \prime}<0$ by the concavity of $q(x)$. Since $\epsilon\left(e_{0}(\gamma)\right)>0$, we hence have $e_{0}<e^{*}$. By (17), which is satisfied in the first best, we have $x_{0}<x^{*}$.

Using (16) the ICC (4) can be rewritten as:

$$
r_{0}=\frac{\epsilon\left(e_{0}\right)}{p^{\prime}\left(e_{0}\right)}+(1-\tau) w>c_{0}=(1-\tau) w .
$$

Lastly, we need to ensure that with this contract the PC is not binding. Using the binding LLC together with the ICC, the PC can be written as

$$
\frac{p\left(e_{0}\right)}{p^{\prime}\left(e_{0}\right)}-e_{0} \geq v
$$

As $p(e)$ is strictly concave by Assumption 1(i), $p(e)>e p^{\prime}(e)$ for all $e>0$ and hence, rearranging terms, $p(e) / p^{\prime}(e)-e>0$ for all $e>0$. Also, due to strict concavity of $p(e)$, it follows directly upon differentiation that $p(e) / p^{\prime}(e)-e$ is strictly increasing for $e>0$ (its slope is $\epsilon(e)>0$ for all $e>0)$. Hence any $e_{0}(\gamma)>0$ will define a $\underline{v}(\gamma)$, given by $\underline{v} \equiv p\left(e_{0}\right) / p^{\prime}\left(e_{0}\right)-e_{0}$, such that for any $v<\underline{v}$ the $\mathrm{PC}$ will not be binding and hence the contract derived above is indeed feasible and optimal. As $e_{0}>0$, it follows that $\underline{v}>0$.

Step 4: For $v \in[\underline{v}(\gamma), \bar{v}(\gamma))$ the optimal contract is characterized by:

$$
\begin{aligned}
r & =q(g(v, \gamma))-\frac{1}{p^{\prime}(f(v))}+(1-\tau) w>(1-\tau) w \\
c & =(1-\tau) w \\
x & =g(v, \gamma)<x^{*}(\gamma)
\end{aligned}
$$

with $e=f(v)<e^{*}(\gamma)$.

Proof of Step 4: We first show that for any $v \geq \underline{v}(\gamma)$ the participation constraint is binding at 
the optimal contract. Suppose it is not. The lenders problem can then be written as in (15). Let the solution to this problem be denoted as $(\hat{e}, \hat{x})$ with $\hat{e}>f(v) .{ }^{44}$ Given $\hat{e}$, the optimal $x$ needs to satisfy the first-order condition: $p(\hat{e})) q^{\prime}(x)=\gamma$. As $\hat{e}>f(v) \geq f(\underline{v})$, surely $\hat{x}>x_{0}$. However, we know that at any $(\hat{e}, \hat{x})$, where $(\hat{e}, \hat{x})$ satisfies the FOC w.r.t. $x$ and $\hat{x}>x_{0}$, it must be true that $p^{\prime}(\hat{e}) q(\hat{x})-\epsilon(\hat{e})<1$. This follows from strict concavity of $p(e) q(e)$ (see step 3). Therefore the FOC w.r.t. $e$ is not satisfied at $(\hat{e}, \hat{x})$ and the lender would want to decrease $\hat{e}$. As the PC is not binding this is possible, contradicting the optimality of $\hat{e}>f(v)$.

As the LLC is binding by step 3, using the ICC we can write the binding PC as:

$$
\frac{p(e)}{p^{\prime}(e)}-e=v .
$$

Recall from step 2 that the left hand side is strictly positive and increasing. We can hence define $f(v)$ as the solution for $e$ which solves the binding PC. We have $f_{v} \equiv \partial f / \partial v=-\left(p^{2} /\left(p p^{\prime \prime}\right)>0\right.$. As $f(\bar{v})=e^{*}$ and $f(v)$ is strictly increasing for all $v \leq \bar{v}$ we know that the optimal contract satisfies $e=f(v)<e^{*}$.

Using the binding $\mathrm{PC}$ we can rewrite the maximization problem as

$$
\max _{\{x\}} p(f(v)) q(x)-f(v)-u-\gamma x
$$

yielding the FOC

$$
p(f(v)) q^{\prime}(x)=\gamma .
$$

Let $g(v, \gamma)$ be the solution for $x$, defined by $p(f(v)) q^{\prime}(g(v, \gamma))=\gamma$. As $f(v)<e^{*}$ it follows that $x=g(v, \gamma)<x^{*}$. It is readily verified that $g_{v} \equiv \partial g / \partial v=-\left(p^{\prime} f_{v} q^{\prime}\right) /\left(p q^{\prime \prime}\right)>0$. It is straightforward to verify that $g_{\gamma}(v, \gamma)<0$. From the ICC

$$
r=q(g(v, \gamma))-\frac{1}{p^{\prime}(f(v))}+(1-\tau) w
$$

Note that $q(g(v, \gamma))-\frac{1}{p^{\prime}(f(v))} \neq 0$ as otherwise $q(g(v, \gamma)) p^{\prime}(f(v))=1$ together with (19) would imply that the first best would be implemented, contradicting $f(v)<e^{*}$. This implies $r \neq c$, implying, by step $1(\mathrm{i})$ that $r>c$.

Lemma 1 Suppose Assumption 1 holds. Then (i) $S(v, \gamma)>0$ for any $v \geq 0$; (ii) $S(v, \gamma)$ is strictly increasing in $v$, with slope less than 1 , for $v \in(\underline{v}(\gamma), \bar{v}(\gamma))$, constant at $S(\underline{v}(\gamma), \gamma)$ for $v \leq \underline{v}(\gamma)$, and constant at $S^{*}(\gamma)$ for $v \geq \bar{v}(\gamma)$; (iii) $S(v, \gamma)$ is everywhere strictly decreasing in $\gamma$

\footnotetext{
${ }^{44}$ The contract is a tuple $(r, c, x)$, but as $c$ is determined by the binding LLC and the ICC holds, the contract can be written in terms of $(e, x)$.
} 
Proof of Lemma 1. Note that $S(\underline{v}, \gamma)=p\left(e_{0}\right) q\left(x_{0}\right)-\gamma x_{0}-e_{0}$ where $\left(x_{0}, e_{0}\right)$ is defined by (16) and (17). By the concavity of $p(e) q(x), p\left(e_{0}\right) q\left(x_{0}\right) \geq p^{\prime}\left(e_{0}\right) q\left(x_{0}\right) e_{0}+p\left(e_{0}\right) q^{\prime}\left(x_{0}\right) x_{0}$. From the definition of $\left(x_{0}, e_{0}\right)$ it follows $p^{\prime}\left(e_{0}\right) q\left(x_{0}\right) e_{0}=e_{0}+\epsilon\left(e_{0}\right) e_{0}$ and $p\left(e_{0}\right) q^{\prime}\left(x_{0}\right) x_{0}=\gamma x_{0}$. Hence $S(\underline{v}, \gamma) \geq \epsilon\left(e_{0}\right) e_{0}>0$ as long as $e_{0}>0$, which is true by Step 3 of the proof of Proposition 2. Observe that

$$
S_{v} \equiv \frac{\partial S}{\partial v}=\left(p^{\prime}(f(v)) q(g(v, \gamma))-1\right) f_{v}(v) .
$$

For $v>\bar{v}, p^{\prime}\left(e^{*}\right) q\left(x^{*}(\gamma)\right)=1$ and also, $f(v)=f(\bar{v})$. Therefore, $S_{v}=0$. Similarly, in the case where the $\mathrm{PC}$ does not bind, i.e., $v<\underline{v}$ from the proof of Proposition $2, e_{0}$ and $x_{0}$ are independent of $v$. Therefore, for $v<\underline{v}(\gamma), S_{v}=0$.

Now consider $\underline{v} \leq v<\bar{v}$. We know $p^{\prime}(f(v)) q(g(v, \gamma))>1$ and $f_{v}(v)=1 / \epsilon(e)$. Recall that at $v=\underline{v}$ we have $p^{\prime}(f(\underline{v})) q(g(\underline{v}, \gamma))-1=\epsilon(f(\underline{v}))$ and hence $S_{v}=1$. Further we know that $\epsilon(e)$ (the denominator) is non-decreasing and we can show that $p^{\prime}(f(v)) q(g(v, \gamma)$ ) (the numerator) is decreasing in $v$. Taking the derivative (and using the expression for $g_{v}$ ) gives $f_{v} /\left(p q^{\prime \prime}\right)\left[p^{\prime \prime} q p q^{\prime \prime}-\right.$ $\left(p^{\prime} q^{\prime 2}\right]$. The term in square brackets is positive by the concavity of $p(e) q(x)$ and we have found the fact that $f_{v}>0$ in the proof of Proposition 2. From Proposition 2, $f(v)>e_{0}$ for $v>\underline{v}$. Hence it follows that for $v \in(\underline{v}, \bar{v})$ we have $0<S_{v}<1$. (As $v \rightarrow \bar{v}, S_{v} \rightarrow 0$ as $p^{\prime}(f(v)) q(g(v, \gamma)) \rightarrow 1$.) Given that we have proved that $S(\underline{v}, \gamma)>0$, this shows that $S(v, \gamma)>0$ for all $v \geq \underline{v}$. To check that $S(v, \gamma)$ is decreasing in $\gamma$, by the envelope theorem: $\frac{\partial S}{\partial \gamma}=\left(p(f(v)) q^{\prime}(g(v, \gamma))-\gamma\right) g_{\gamma}(v, \gamma)-$ $g(v, \gamma)=-g(v, \gamma)$. This expression being negative for all $v \geq 0$ and $\gamma \geq 0$, the proof is complete.

Lemma 2 Suppose Assumption 1 holds. For a given level of $(1-\tau) w$ there is a unique threshold $\bar{u}((1-\tau) w, \gamma)$ where $\bar{u}+(1-\tau) w>\underline{v}(\gamma)$, such that there is no borrowing if and only if $u>\bar{u}$.

Proof of Lemma 2. Assume $v<\bar{v}$. Let $g$ and $f$ denote the optimal choices of $x$ and $e$ as derived in Proposition 2, suppressing the arguments for notational simplicity. For a lender to make a non-negative profit his expected revenue needs to exceed his cost of funds. This is the case if and only if:

$$
(1-p(f))(1-\tau) w+p(f)\left((1-\tau) w+q(g)-\frac{1}{p^{\prime}(f)}\right)-\gamma g \geq 0
$$

Consider the case where $v \leq \underline{v}$. Recall from the proof of Proposition 2 that $\left(x_{0}, e_{0}\right)$ maximize the left hand side of the above condition and the objective function is positive at the optimum. As a result, credit will be given for all $v \leq \underline{v}$. Therefore, if a $u$ exists such that the borrower does not borrow, it must be the case that $u>\underline{v}-w(1-\tau)$.

Now consider the case where $\underline{v}<v<\bar{v}$. Using $p(f) / p^{\prime}(f)-f=v$ and $v=u+(1-\tau) w$ the condition can be rewritten as

$$
p(f) q(g)-f-\gamma g-u \geq 0
$$


or, $S(v, \gamma) \geq u$. By an analogous argument, for $v \geq \bar{v}$, the condition for credit to be given is $S^{*}(\gamma) \geq u$. From Lemma 1 we know that for $v \geq \bar{v}$ and $v \leq \underline{v}$ we have $\frac{\partial S}{\partial v}=0$ and that $S_{v}<1$ for $v \in(\underline{v}, \bar{v})$. Therefore $\partial S / \partial u=S_{v}<1$ for $v \in(\underline{v}, \bar{v})$. Hence there exists a unique $\bar{u}((1-\tau) w, \gamma)$ defined by $S((1-\tau) w+\bar{u}, \gamma)=\bar{u}$. And $S(v, \gamma) \geq($ or $<) u$ if and only if $u$ is $\leq($ or $>) \bar{u}$.

Proof of Proposition 3. Suppose that the high cost lender earns a profit of $\pi_{\bar{\gamma}}>0$. Then we must have $u_{\bar{\gamma}} \geq u_{\underline{\gamma}}$ for the borrower to borrow from him. But then $S\left(u_{\bar{\gamma}}+(1-\tau) w, \underline{\gamma}\right)>$ $S\left(u_{\underline{\gamma}}+(1-\tau) w, \bar{\gamma}\right)$ by Lemma 1 and so the more efficient lender can offer $u_{\bar{\gamma}}$ while earning a profit $\pi_{\underline{\gamma}}>\pi_{\bar{\gamma}}>0$. Therefore in equilibrium, we must have $\pi_{\bar{\gamma}}=0$. Now consider two cases. First assume that the PC is binding in equilibrium as far as the low cost lender is concerned, i.e. $u_{\bar{\gamma}}+(1-\tau) w \geq \underline{v}(\underline{\gamma})$. Then by the previous argument, $u_{\underline{\gamma}}=u_{\bar{\gamma}}$ and $u_{\bar{\gamma}}$ will be given by $\bar{u}((1-\tau) w, \bar{\gamma})$. Hence it must be true that $\bar{u}((1-\tau) w, \bar{\gamma})+(1-\bar{\tau}) w \geq \underline{v}(\underline{\gamma})$. Conversely, assume that $\bar{u}((1-\tau) w, \bar{\gamma})+(1-\tau) w \geq \underline{v}(\underline{\gamma})$. Then it cannot be the case that the efficient lender offers a contract which gives utility smaller than $\bar{u}((1-\tau) w, \bar{\gamma})$ to the borrower, as this would allow the inefficient lender to make a profit. However, then it needs to be the case that the PC is binding. Hence, the $\mathrm{PC}$ is binding if and only if $\bar{u}((1-\tau) w, \bar{\gamma})+(1-\tau) w \geq \underline{v}(\underline{\gamma})$. If the condition fails to hold, then the PC is not binding and the borrower's utility is given by $\underline{v}(\underline{\gamma})-(1-\tau) w$. The monotonicity result follows from the fact that holding $\underline{\gamma}$ constant, reducing $\bar{\gamma}$ will increase $\bar{u}((1-\tau) w, \bar{\gamma})$ (again, from Lemma 1$)$

Proof of Proposition 4. Consider $v \geq \underline{v}(\gamma)$. The limited liability effect follows directly from the Lemma 1: $S(v, \gamma)$ is increasing in $v$ and $v$ is decreasing in $\tau$. If the outside option of the borrower is constant, the lender receives all the gain in surplus. However, with competition the outside option of the borrower is non-decreasing, as $\bar{u}$ is non-decreasing in $\tau$. This follows directly from the definition of $\bar{u}$ in Lemma 2 and $S_{v} \geq 0$.

Consider $v<\underline{v}(\gamma)$. The payoff of a borrower in this case is given by

$$
u_{0}=\underline{v}(\gamma)-(1-\tau) w
$$

which is increasing in $\tau$.

Proof of Proposition 5. Assume that the result postulated in part 1 of Proposition 5 does not hold. Then it must be the case that for some $w$ small enough an efficiency utility is offered (i.e., the PC does not bind). By definition $S(\underline{v}, \gamma)=\pi_{0}+u_{0}=\pi_{0}+\underline{v}-w(1-\tau)$. From the proof of Proposition 2 recall that $\pi_{0}=p\left(e_{0}\right)\left(q\left(x_{0}\right)-1 / p^{\prime}\left(e_{0}\right)\right)-\gamma x_{0}+w(1-\tau)>0$ even for $w=0$. Hence $p\left(e_{0}\right)\left(q\left(x_{0}\right)-1 / p^{\prime}\left(e_{0}\right)\right)-\gamma x_{0}>0$ and it follows that $S(\underline{v}(\bar{\gamma}), \bar{\gamma})>\underline{v}(\bar{\gamma})$. For $\bar{\gamma}$ close to $\underline{\gamma}$ we know $\underline{v}(\underline{\gamma})$ is close to $\underline{v}(\bar{\gamma})$ by continuity and monotonicity. Hence it must be true that $S(\underline{v}(\bar{\gamma}), \bar{\gamma})>\underline{v}(\underline{\gamma})$. As the outside option is at least $S(\underline{v}(\bar{\gamma}), \bar{\gamma})$ and $v=w(1-\tau)+u$, even for $w=0$ the $\mathrm{PC}$ will be binding, i.e. $v>\underline{v}(\underline{\gamma})$. As their outside options go up, borrowers are 
better off. To show that the efficient lender is better off, observe that his profits are given by

$$
\pi(z)=S(z, \underline{\gamma})-S(z, \bar{\gamma})
$$

where $z \equiv \bar{u}((1-\tau) w, \bar{\gamma})+w(1-\tau)$. Observe that $\partial \pi(z) / \partial z=S_{1}(z, \underline{\gamma})-S_{1}(z, \bar{\gamma})$ which is positive if $S_{12}(z, \gamma)<0$. This indeed is the case as using the envelope theorem, we have:

$$
\frac{\partial S}{\partial \gamma}=-g(v, \gamma) \text { and } \frac{\partial^{2} S}{\partial \gamma \partial v}=-g_{\gamma}(v, \gamma)<0 .
$$

Part 2 follows directly from Part 2 of Proposition 4.

Proof of Proposition 6. Let $F$ be the fixed cost that a lender incurs to make any non-negative loan to the borrower. Introducing a fixed cost we have the following identity:

$$
S-F=u+\pi .
$$

First consider the case $v \leq \underline{v}$. Recall $u_{0}(w)=\underline{v}-(1-\tau) w$ from the proof of Proposition 4. The lender will provide a loan whenever he makes positive profits, i.e. $S(\underline{v})-u_{0}(w)-F \geq 0$ or

$$
(1-\tau) w \geq F-S(\underline{v})+\underline{v} .
$$

Let $\underline{w}_{0}(F ; \gamma)$ be the wealth level which satisfies this with equality. This is the wealth threshold such that a lender would provide a positive loan if and only if the borrower has wealth $w>$ $\underline{w}_{0}(F ; \gamma)$. Note that $F>S(\underline{v})-\underline{v}$ implies $\underline{w}_{0}>0$, and the threshold $\underline{w}_{0}$ is increasing in $F$ and independent of $u$.

Next consider the case $v \in(\underline{v}, \bar{v})$. Define $\hat{u}(F ; \gamma) \equiv \underline{v}-(1-\tau) \cdot \underline{w}_{0}(F ; \gamma)$. Consider a borrower with $u \leq \hat{u}(F ; \gamma)$. As $v>\underline{v}$, it must be that $w>\underline{w}_{0}(F ; \gamma)$. But since $S$ is non-decreasing in $w$, a lender will make positive profits from lending to this borrower. Hence for any individual with $u \leq \hat{u}(F ; \gamma)$ the wealth threshold below which he cannot borrow is given by $\underline{w}_{0}$. Now consider a borrower with $u>\hat{u}(F ; \gamma)$. Setting $\pi=0$ in (20) then defines $\underline{w}(F, u ; \gamma) \geq 0$ such that a lender would provide a positive loan if and only if the borrower has wealth $w>\underline{w}(F, u ; \gamma)$. Given the properties of $S(v, \gamma)$, the threshold $\underline{w}(F, u ; \gamma)$ is non-decreasing in $F$ and $u$.

Note that $\underline{w}(F, \hat{u} ; \gamma)=\underline{w}_{0}(F ; \gamma)$ and recall that $\underline{w}(F, u ; \gamma)$ is increasing in $u$. Hence the wealth threshold below which no credit is provided is non-decreasing in $u$. Therefore, for all $u$ there exists a strictly positive wealth threshold below which now credit is provided.

Timothy J. Besley, London School of Economics, IIES And CIFAR

Konrad B. Burchardi, London School of Economics and IIES

Maitreesh Ghatak, London School of Economics 


\section{References}

Acemoglu, D. and S. Johnson (2005). Unbundling institutions. Journal of Political Economy 113(5), 949-995.

Acemoglu, D., S. Johnson, and J. A. Robinson (2001). The colonial origins of comparative development: An empirical investigation. American Economic Review 91 (5), 1369-1401.

Banerjee, A. V. (2003). Contracting constraints, credit markets and economic development. In L. P. H. Mathias Dewatripont and S. Turnovsky (Eds.), Advances in Economics and Econometrics: Theory and Applications, Volume III of Eighth World Conference of the Econometric Society, pp. 1-46. Cambridge: Cambridge University Press.

Banerjee, A. V. and E. Duflo (2010, Summer). Giving credit where credit is due. Journal of Economic Perspectives 24(3), 61-80.

Bardhan, P. (2007). Law and development. In A. Dutt and J. Ros (Eds.), International Handbook of Development Economics, Volume II. Elgar.

Bauer, P. (1954). West African Trade. Cambridge: Cambridge University Press.

Besley, T. (1995). Property rights and investment incentives: Theory and evidence from ghana. Journal of Political Economy 103(5), 903-937.

Besley, T. and M. Ghatak (2009). Property rights and economic development. In D. Rodrik and M. Rosenzweig (Eds.), Handbook of Development Economics, Volume V. Amsterdam: Elsevier.

De Mel, S., D. McKenzie, and C. Woodruff (2008, November). Returns to capital in microenterprises: Evidence from a field experiment. The Quarterly Journal of Economics 123(4), 1329-1372.

De Soto, H. (2000). The Mystery of Capital: Why Capitalism Triumphs in the West and Fails Everywhere Else. New York, London: Basic Books, Bantam Press/Random House.

De Soto, H. (2001). The mystery of capital. Finance and Development (IMF) 38(1).

Deininger, K. and G. Feder (2009). Land registration, governance, and development: Evidence and implications for policy. The World Bank Research Observer 24(2), 233-266.

Di Tella, R., S. Galiant, and E. Schargrodsky (2007). The formation of beliefs: Evidence from the allocation of land titles to squatters. Quarterly Journal of Economics 122(1), 209-241.

Djankov, S., C. McLiesh, and A. Shleifer (2007). Private credit in 129 countries. Journal of Financial Economics 84(2), 299-329.

Fafchamps, M., D. McKenzie, S. R. Quinn, and C. Woodruff (2011, July). When is capital enough to get female microenterprises growing? evidence from a randomized experiment in ghana. Working Paper 17207, National Bureau of Economic Research.

Field, E. (2005). Property rights and investment in urban slums. Journal of the European Economic Association Papers and Proceedings 3(2-3), 279-290. 
Field, E. (2007). Entitled to work: Urban property rights and labor supply in peru. Quarterly Journal of Economics 122(4), 1561-1602.

Field, E. and M. Torero (2008). Do property titles increase credit access among the urban poor? evidence from a nationwide titling program. Working paper, Harvard University.

Galiani, S. and E. Schargrodsky (2010, August). Property rights for the poor: Effects of land titling. CEDLAS, Working Papers 0103, CEDLAS, Universidad Nacional de La Plata.

Genicot, G. (2002). Bonded labour and serfdom: A paradox of voluntary choice. Journal of Development Economics 67(1), 101-127.

Genicot, G. and D. Ray (2006). Bargaining power and enforcement in credit markets. Journal of Development Economics 79(2), 398-412.

Goldstein, M. and C. Udry (2008, December). The profits of power: Land rights and agricultural investment in ghana. Journal of Political Economy 116(6), 981-1022.

Hornbeck, R. (2010). Barbed wire: Property rights and agricultural development. The Quarterly Journal of Economics 125(2), 767-810.

Innes, R. D. (1990, October). Limited liability and incentive contracting with ex-ante action choices. Journal of Economic Theory 52(1), 45-67.

Johnson, S., J. McMillan, and C. Woodruff (2002). Property rights and finance. American Economic Review 92(5), 1335-1356.

Kranton, R. and A. Swamy (1999). The hazards of piecemeal reform: British civil courts and the credit markets in colonial india. Journal of Development Economics 58(1), 1-24.

La Porta, R., F. Lopez-de-Silanes, A. Shleifer, and R. W. Vishny (1998, December). Law and finance. Journal of Political Economy 106(6), 1113-1155.

Liberti, J. M. and A. R. Mian (2010). Collateral spread and financial development. The Journal of Finance 65(1), 147-177.

Rodrik, D. (2008). One Economics, Many Recipes: Globalization, Institutions, and Economic Growth. Princeton: Princeton University Press.

Stiglitz, J. E. (1988). Economic organization, information, and development. In H. B. Chenery and T. N. Srinivasan (Eds.), Handbook of Development Economics, Chapter 5, pp. 93-160. Amsterdam: Elsevier.

Woodruff, C. (2001, December). Review of de soto's the mystery of capital. Journal of Economic Literature 39(4), 1215-1223. 


\section{Tables}

TABLE I

Estimation Results

\begin{tabular}{lcc|c}
\hline \hline & \multicolumn{2}{c|}{ SRI LANKA } & GHANA \\
& $(1)$ & $(2)$ & $(3)$ \\
\hline \multicolumn{3}{c}{$\log$ (Profits) } \\
\hline \multirow{3}{*}{$\log$ (Capital) } & $0.570^{* * *}$ & $0.564^{* * *}$ & $0.566^{* * *}$ \\
& $(0.115)$ & $(0.139)$ & $(0.166)$ \\
Constant & $-2.089^{* * *}$ & $-2.098^{* * *}$ & 1.216 \\
& $(0.097)$ & $(0.133)$ & $(0.893)$ \\
$\mathrm{N}$ & 3102 & 1986 & 4100 \\
& & & \\
\hline
\end{tabular}

Notes: The table shows results from instrumental variable regressions. We instrument for the level of business capital with the amount of money and value of assets provided experimentally. We use the same sample as MMW (2008). Standard errors heteroscedasdicity robust. No fixed effects are included. In column 1 and 2 profits and business capital are measured in Sri Lankan Rupees, deflated by the Sri Lanka Consumers Price Index to reflect April 2005 price levels and divided by 45760 to normalise them to the value of a year's labour endowment. The sample size in columns 1 and 2 refers to the number of observations in an The sample size in columns 1 an were not borrowing at baseline. In column 3 profits and business capital are measured in Ghanian cedi and are not normalised. The sample size refers to the number of observations in a panel of 790 firms. The regression result from column 3 has been provided to us by David McKenzie and uses the data presented in FMQW (2011). 


\section{Figures}

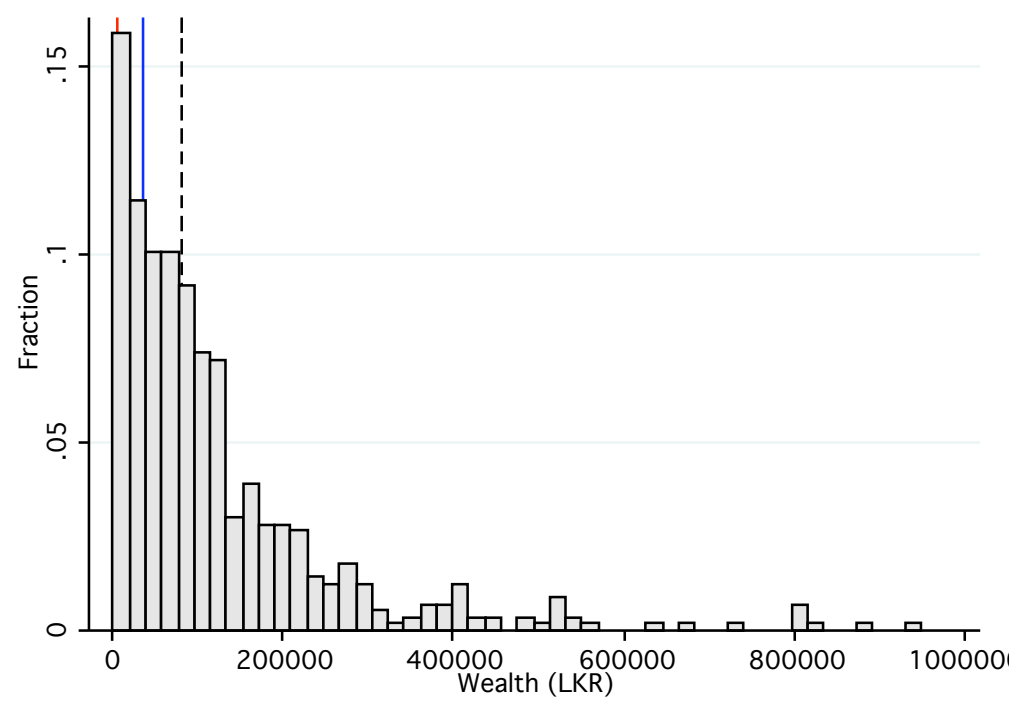

FiguRE I

Wealth Distribution (SRi Lanka)

Notes: The figure is a histogram of the distribution of wealth in Sri Lanka. The data is taken from the baseline survey of small scale entrepreneurs of the MMW study. Wealth is measured as the sum of the total replacement costs of all business assets and the market value of the inventories. The histogram shows 50 bins between 0 and 100.000 LKR. It uses data from 568 observations. We truncated the histogram at a wealth of 100.000 LKR for expositional clarity and this way excluded 10 observations. The vertical lines correspond to the 5 th, 25 th and 50 th percentile of the wealth distribution in the non-truncated data. 

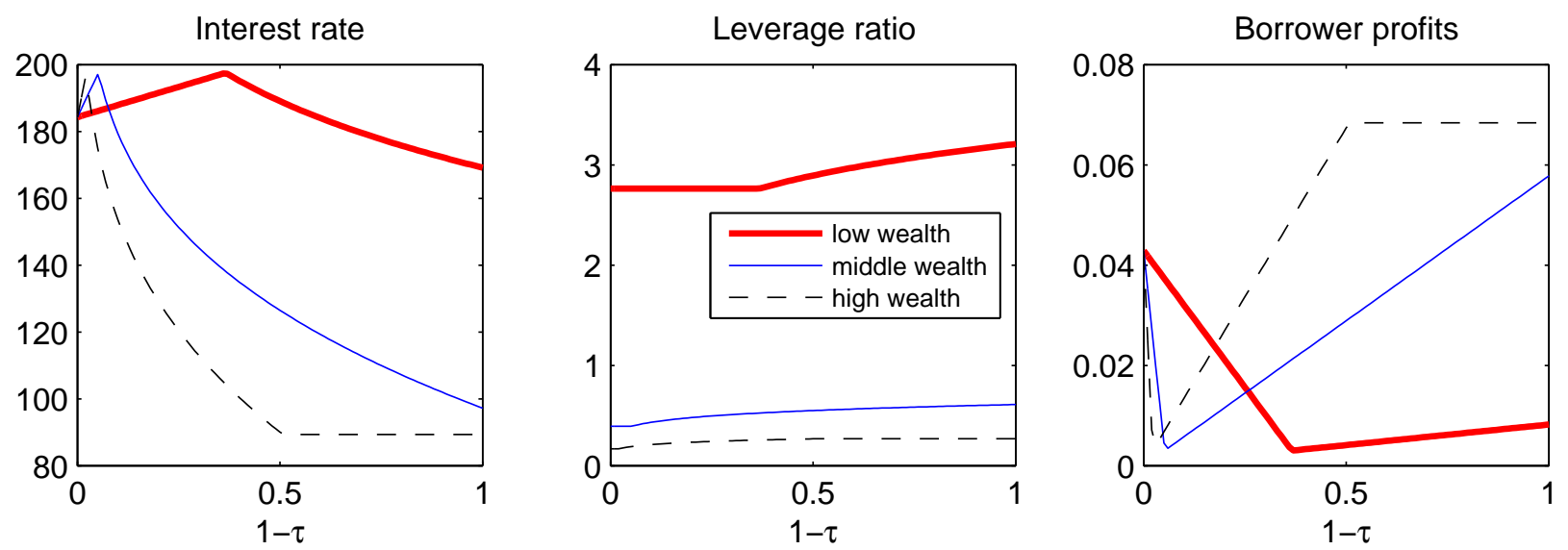

No Competition (SRi Lanka)

Notes: The figure shows the predicted interest rate $(r / x-1) / 100$, the leverage ratio $(x / w)$, and the borrower's profits, $p(e)(q(x)-$ $r)-(1-p(e)) c$, as a function of the extent to which capital can be collateralized as measured by $(1-\tau)$. The borrower's profit is given as a fraction of the value of a year's labour endowment. Results are shown for three wealth levels, corresponding to the 5th (bold lines), 25th (solid lines) and 50th percentiles (dashed lines) of the wealth distribution in Sri Lanka. The data on the wealth distribution is taken from the baseline survey of MMW and depicted in Figure I. The model is parametrised using data from Sri Lanka, as explained in Section 5.2. The results presented are for the case where the outside option is autarky, i.e. $\bar{u}=0$, corresponding to the case of a monopolistic lender. 

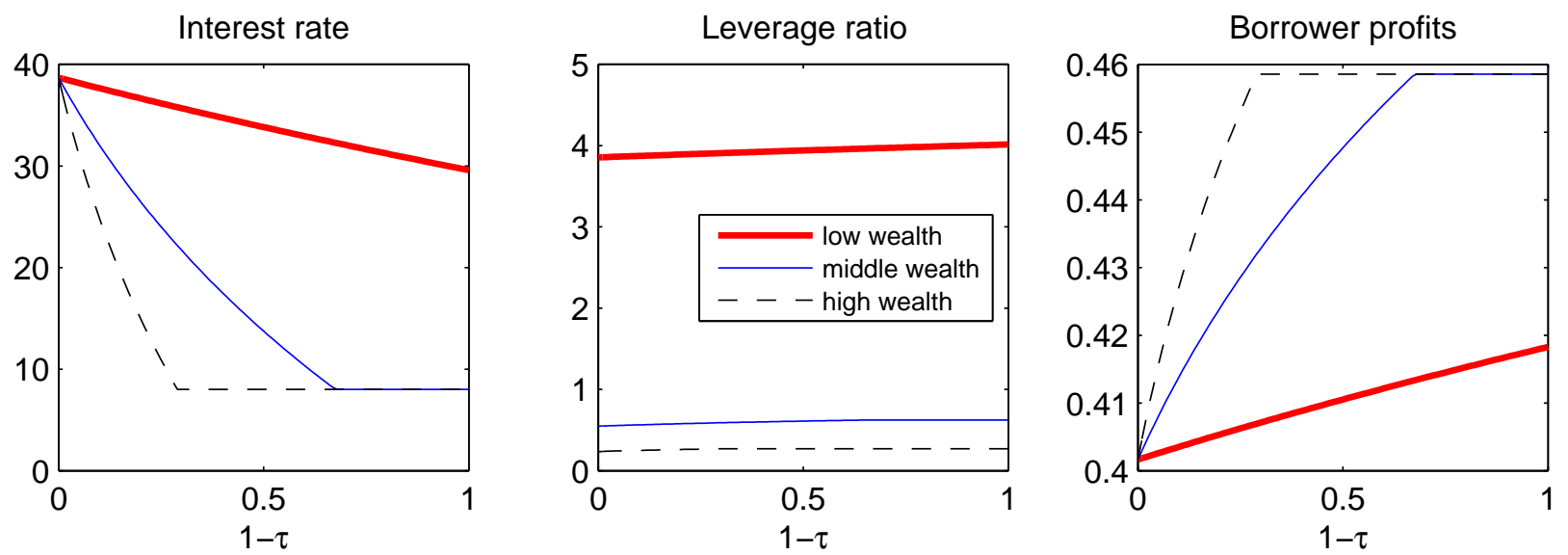

\section{FIGURE III}

Competition (SRi LANKA)

Notes: The figure shows the predicted interest rate $(r / x-1) / 100$, the leverage ratio $(x / w)$, and the borrower's profits, $p(e)(q(x)-$ $r)-(1-p(e)) c$, as a function of the extent to which capital can be collateralized as measured by $(1-\tau)$. The borrower's profit is given as a fraction of the value of a year's labour endowment. Results are shown for three wealth levels, corresponding to the 5th (bold lines), 25th (solid lines) and 50th percentiles (dashed lines) of the wealth distribution in Sri Lanka. The data on the wealth distribution is taken from the baseline survey of MMW and depicted in Figure I. The model is parametrised using data from Sri Lanka, as explained in Section 5.2. The results presented are for the case where the outside option is given by a second lender with the same cost of funds (nominal interest rate of $8 \%$ ), corresponding to the perfectly competitive case. 

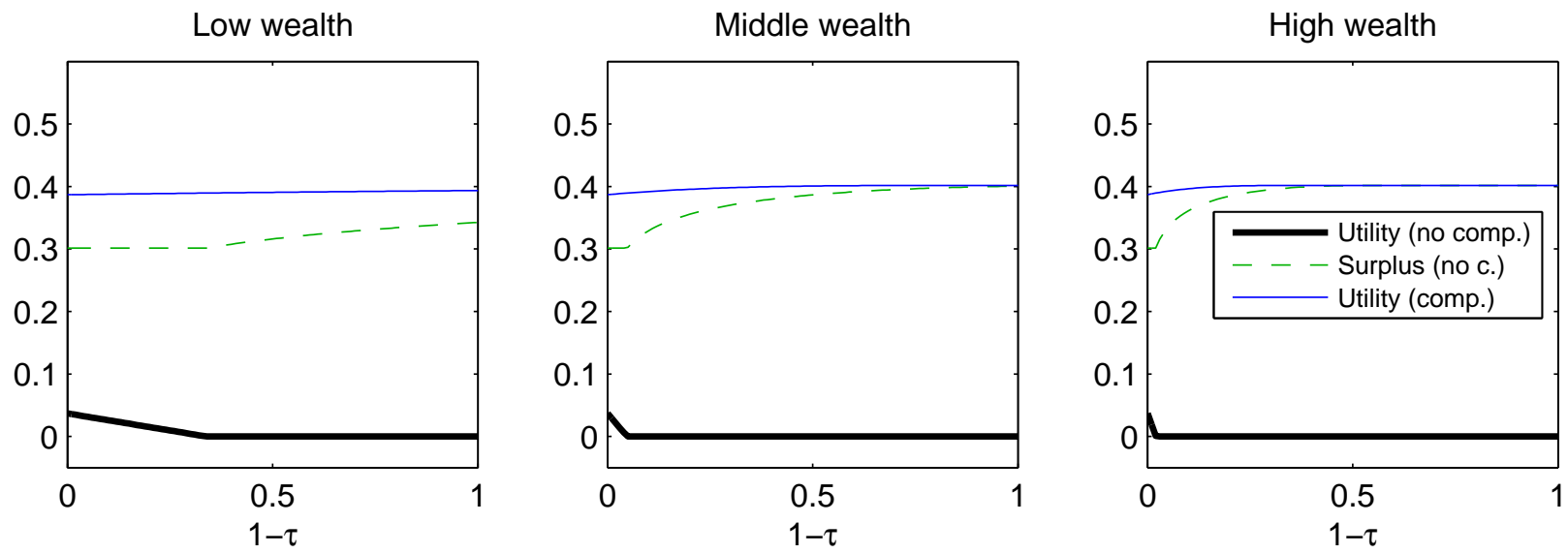

FigURE IV

WELFARE

Notes: The figure presents the total surplus (dashed green line) and the utility of the borrower (thick black line) for the case where competition is absent, as well as the borrowers' utility in the perfectly competitive case (solid blue line) as a function of the extent to which capital can be collateralized as measured by $(1-\tau)$. All these quantities are given as a fraction of the value of a year's labour endowment. Results are shown for three wealth levels separately, corresponding to the 5th (bold lines), 25th (solid lines) and 50th percentiles (dashed lines) of the wealth distribution in Sri Lanka. The data on the wealth distribution is taken from the baseline survey of MMW and depicted in Figure I. The model is parametrised using data from Sri Lanka, as explained in Section 5.2. In the monopolistic case we assumed $\bar{u}=0$, and in the perfectly competitive case we assume that the outside option is given by a second lender with the same cost of funds (a nominal interest rate of $8 \%$ ). 

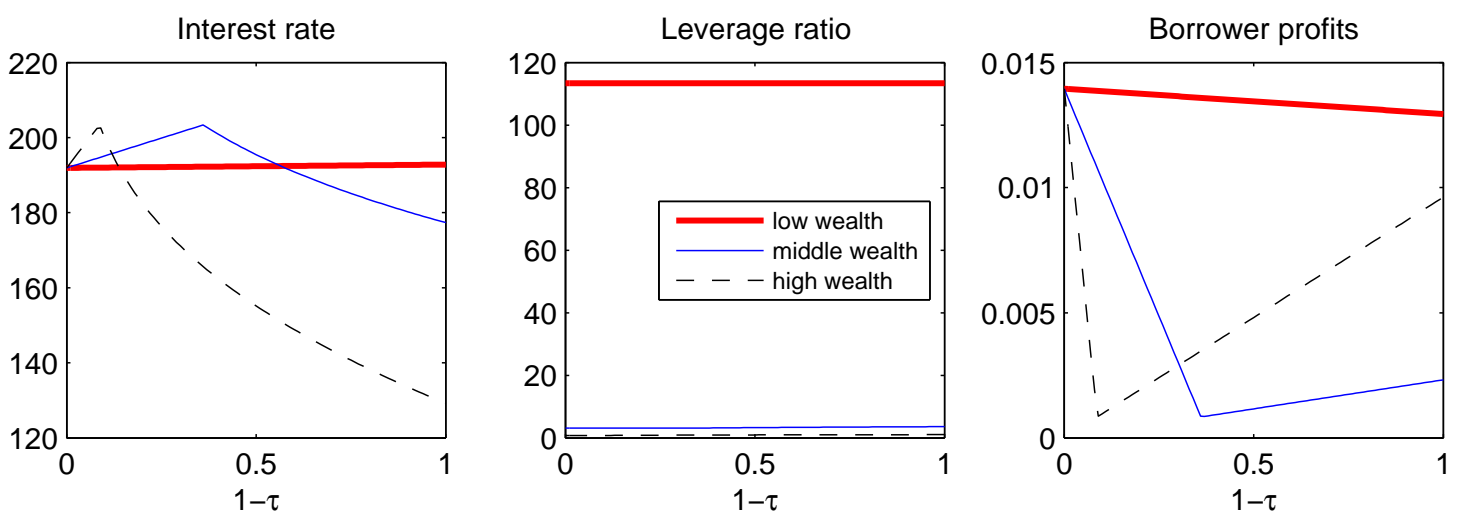

(A) No COMpetition
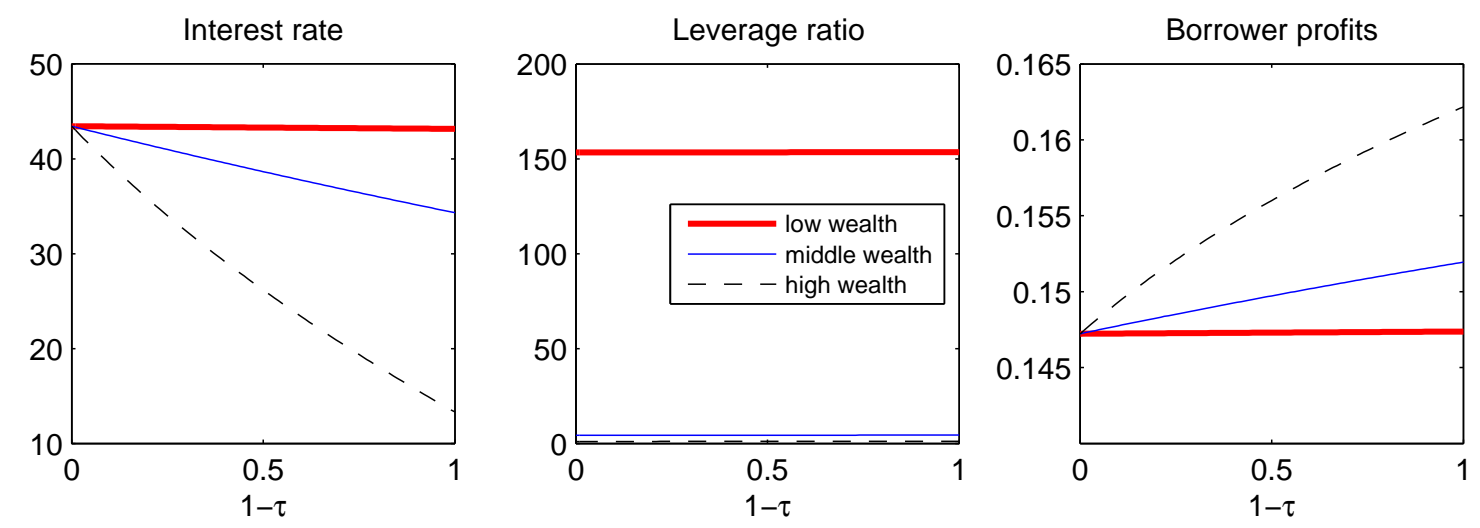

(в) Competition
Figure V
Main Results (Ghana)

Notes: Both Subfigures (A) and (B) show the predicted interest rate $(r / x-1) / 100$, the leverage ratio $(x / w)$, and the borrower's profits, $p(e)(q(x)-r)-(1-p(e)) c$, as a function of the extent to which capital can be collateralized as measured by $(1-\tau)$. The borrower's profit is given as a fraction of the value of a year's labour endowment. In Subfigure (A) we assume that the outside option is given by $\bar{u}=0$, corresponding to the case of a monopolistic lender. In Subfigure (B) we assume that the outside option is given by a second lender with the same cost of funds (we assume a nominal interest rate of $8 \%$ ), corresponding to the perfectly competitive case. In both Subfigures results are shown for three wealth levels, corresponding to the 33rd (bold lines), 50th (solid lines) and 66th percentiles (dashed lines) of the wealth distribution in Ghana. The data on the wealth distribution is taken from the baseline survey of FMQW and was provided to us by David McKenzie. The model is parametrised using data from Ghana, as explained in Section 5.5.3. 

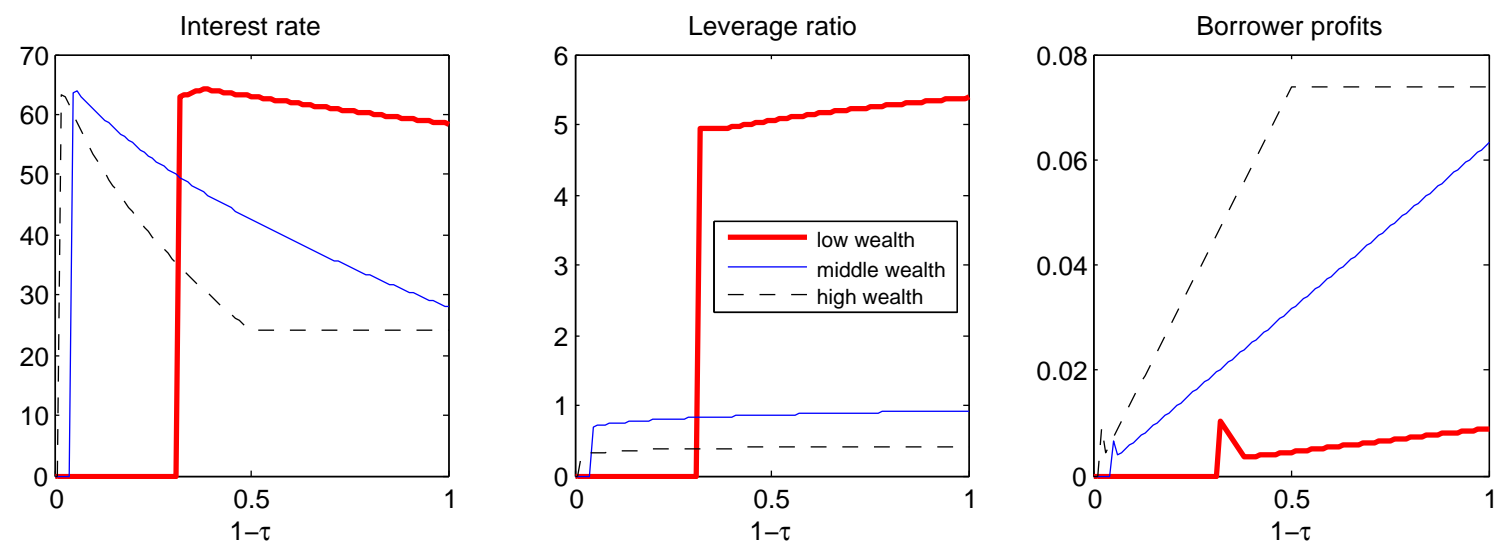

(A) Fixed Cost, no COMpetition
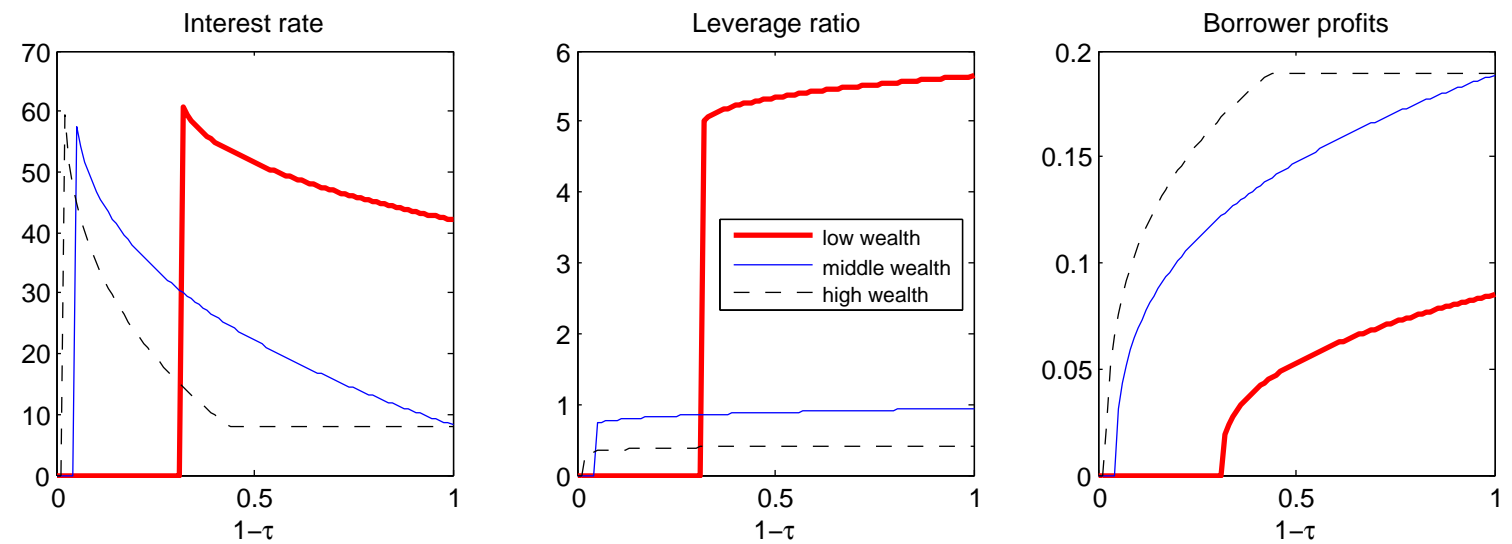

(B) Fixed Cost, COMpetition

Figure VI

Results With FiXed COST, $F=0.25$ (SRI LANKA)

Notes: Both Subfigures (A) and (B) show the predicted interest rate $(r / x-1) / 100$, the leverage ratio $(x / w)$, and the borrower's profits, $p(e)(q(x)-r)-(1-p(e)) c$, as a function of the extent to which capital can be collateralized as measured by $(1-\tau)$. The borrower's profit is given as a fraction of the value of a year's labour endowment. In Subfigure (A) we assume that the outside option is given by $\bar{u}=0$, corresponding to the case of a monopolistic lender. In Subfigure (B) we assume that the outside option is given by a second lender with the same cost of funds (we assume a nominal interest rate of $8 \%$ ), corresponding to the perfectly competitive case. In both Subfigures we parametrise the model with a fixed cost as outlined in Section 6.1, and we assume $F=0.25$. The model is parametrised using data from Sri Lanka, as explained in Section 5.2. Results are shown for three wealth levels, corresponding to the 5th (bold lines), 25th (solid lines) and 50th percentiles (dashed lines) of the wealth distribution in Sri Lanka and depicted in Figure I. 